Portland State University

PDXScholar

Fall 11-10-2016

\title{
The Role of Recovery from Work in Work Stress- Related Drinking
}

Brittnie Renae Shepherd

Portland State University

Follow this and additional works at: https://pdxscholar.library.pdx.edu/open_access_etds

Part of the Psychology Commons

Let us know how access to this document benefits you.

Recommended Citation

Shepherd, Brittnie Renae, "The Role of Recovery from Work in Work Stress-Related Drinking" (2016). Dissertations and Theses. Paper 3340.

https://doi.org/10.15760/etd.5237

This Thesis is brought to you for free and open access. It has been accepted for inclusion in Dissertations and Theses by an authorized administrator of PDXScholar. Please contact us if we can make this document more accessible: pdxscholar@pdx.edu. 
The Role of Recovery from Work in Work Stress-Related Drinking

by

Brittnie Renae Shepherd

A thesis submitted in partial fulfillment of the requirements for the degree of

Master of Science

in

Psychology

Thesis Committee:

Charlotte Fritz, Chair

Leslie Hammer

Cynthia Mohr

Portland State University

2016 


\begin{abstract}
Alcohol consumption has been linked to numerous adverse health and well-being outcomes; therefore determining what motivates individuals to drink is of utmost importance. One reason individuals may drink is to cope with work demands and their associated strain. This may be especially relevant for correctional officers (COs) as this occupation has been associated with high levels of job stressors and strain and heavy drinking. Drawing primarily on the job demands-resources and ego depletion models, this study examined how emotional job demands contribute to $\mathrm{CO}$ exhaustion and alcohol use. Additionally, interactions between common recovery from work experiences and exhaustion were tested to determine if recovery experiences could serve as a protective influence against work stress-related drinking. Participants were 1,370 correctional officers from 14 correctional facilities within the state of Oregon. Results indicate that exhaustion was positively related to both drinking quantity and drinking frequency and that emotional job demands had significant indirect effects on both types of drinking behaviors through employee exhaustion. The recovery experiences relaxation and detachment significantly moderated the relationship between exhaustion and drinking quantity, but not drinking frequency. Mastery experiences did not influence the strength of the positive relationship between exhaustion and either drinking outcome. These findings suggest that engaging in certain recovery experiences may lead to drinking fewer drinks on days when drinking, however the frequency of those days remains unaffected.
\end{abstract}




\section{Acknowledgements}

I would like to acknowledge my committee, Drs. Charlotte Fritz, Cynthia Mohr, and Leslie Hammer, for the opportunities and support they provided throughout this process. I would also like to acknowledge Drs. Craig and Diana Shepherd for their unwavering love and encouragement. 


\section{Table of Contents}

Abstract




\section{List of Tables}

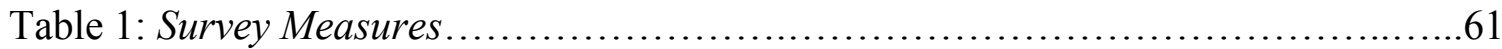

Table 2: Descriptive Statistics and Zero-Order Correlations of Study Variables............63

Table 3: Hypothesized Direct and Interaction Effects on CO Drinking and Exhaustion .64

Table 4: Indirect Effect of Emotional Demands on CO Drinking Through Exhaustion....64

Table 5: Second-stage Moderated Mediation Model of Emotional Demands on Drinking Through Exhaustion with Recovery Experiences as Moderators......................................64

Table 6: Direct and Interaction Effects on CO Drinking and Disengagement ............64

Table 7: Indirect Effect of Emotional demands on CO Drinking Through Disengagement

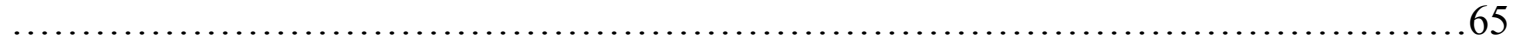

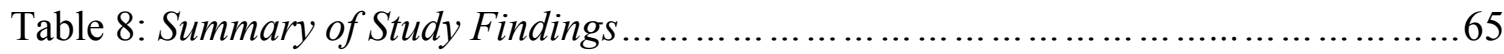




\section{List of Figures}

Figure 1: Hypothesized Conceptual Model...........................................66

Figure 2: Research Question 1 Conceptual Model....................................67

Figure 3: Research Question 2 Conceptual Model....................................68

Figure 4: Research Question 3 Conceptual Model....................................69

Figure 5: Additional Analyses Conceptual Model: Disengagement as a Mediator........70

Figure 6: Pie Chart: Average Drinks Per Day When Drinking..........................71

Figure 7: Graph of the Interaction Between Exhaustion and Relaxation..................72

Figure 8: Graph of the Interaction Between Exhaustion and Detachment.................72 


\section{Introduction}

Excessive drinking is a leading cause of premature mortality in the U.S. accounting for about 1 in 10 deaths among working-age adults (Stahre, Roeber, Kanny, Brewer, \& Zhang, 2014). One estimate put the costs of alcohol misuse in the U.S. at about 223 billion a year in health care costs, lost productivity, and other costs including criminal justice expenses and motor vehicle accidents (Bouchery, Harwood, Sacks, Simon, \& Brewer, 2011). Within the U.S. workforce, 75\% of workers reported drinking alcohol in the past year, although only about $37 \%$ were doing so frequently (Frone, 2013). Impairment estimates for a 12 month period report that about $29 \%$ of workers drink to intoxication and $38 \%$ report drinking alcohol within two hours of leaving work (Frone, 2013). These findings are problematic for both employees and employers alike, considering the potential of alcohol to adversely impact safety at work (Frone, 2004), work performance (Blum, Roman, \& Martin, 1993), and cognitive and motor functioning (Fillmore \& Vogel-Sprott, 2000). Additionally, employee alcohol use has been linked to increased absenteeism (McFarlin \& Fals-Stewart, 2002) and reduced contextual performance (Lehman \& Simpson, 1992). It is clear that employee alcohol use can impact workplace outcomes, but the workplace may also influence employee alcohol use. Therefore it is critical that the workplace antecedents of alcohol use and potential buffers between these antecedents and actual use are identified.

Faced with the negative consequences of alcohol use, researchers have long examined what motivates individuals to consume alcohol in the first place. According the 
tension reduction hypothesis (Conger, 1956), individuals may drink alcohol to reduce or cope with feelings of tension or stress. This potentially maladaptive way of managing stressors and their associated strain is often associated with negative psychological or behavioral outcomes (Adams, Boscarino, \& Galea, 2006). Drinking to cope has been associated with an increased risk of drinking problems as compared to alcohol use associated with other types of drinking motives, such as for social or enhancement reasons (Cooper, 1994).

One way in which stressors may be linked to alcohol use is through experienced strain. It is well established in the literature that high job demands lead to strain reactions and eventual exhaustion if employees have inadequate resources to deal with those demands (Demerouti, Bakker, \& Schaufeli, 2005). Job demands refer to aspects of the job that require sustained effort and as such are associated with psychological or physiological costs when demands exceed an employee's capacity to deal with them (Demerouti et al., 2005). There has been a shift in the past few decades from more physical or mental job demands to more emotional demands as the nature of work changes as result of a rapidly growing service sector (Le Blanc, Bakker, Peeters, van Heesch, \& Schaufeli, 2001). Emotional demands are demands in the workplace that require employees to deal with emotionally charged situations or events (Van Veldhoven \& Meijman, 1994), such as emotionally demanding interactions with clients or coworkers. These types of job demands in particular contribute to exhaustion, a main component of employee burnout that has been associated with a number of adverse 
outcomes for employees, including elevated alcohol use (Maslach, 1978). This state of exhaustion is typically characterized as a feeling of being depleted of emotional and physical resources (Maslach, Schaufeli, \& Leiter, 2001). Resources refer to “objects, personal characteristics, conditions, or energies that are valued by the individual" and may include experiences like mastery and self-esteem (Hobfoll, 1989, p. 516). A lack of necessary resources to deal with job demands can translate into various issues for employees, such as high levels of emotional exhaustion, need for recovery (Sonnentag, Kuttler, \& Fritz, 2010), psychosomatic complaints, decreased work engagement (Sonnentag, Binnewies, \& Mojza, 2010), burnout and decreased life satisfaction (Sonnentag \& Fritz, 2014). Therefore protecting these resources from depletion due to exposure to work demands and their subsequent strain is crucial.

While precise definitions may differ between models, work strain as conceptualized here is the result of an imbalance between job demands and available resources (Bakker \& Demerouti, 2007). When job demands are high and resources are low, strain reactions are likely to occur. Work strain has been associated with numerous adverse outcomes such as increases in employee absenteeism, psychological illness, and physical illness (Darr \& Johns, 2008). In addition, strain may increase health risk behaviors such as heavy alcohol consumption (Siegrist \& Rodel, 2006) or interact with heavy alcohol consumption leading to elevated blood pressure and risk for cardiovascular disease (Schnall, Schwartz, Landsbergis, Warren, \& Pickering, 1992). This may be especially relevant for correctional officers (COs) as this occupation has been associated 
with high levels of various job stressors and strains, as well as poor health and well-being outcomes. While there is some evidence to support a direct relationship between work strain and increased alcohol consumption (Frone, 1999; 2008), recent research supports a more indirect relationship between work strain and alcohol use, indicating the presence of potential intervening variables, as elaborated below.

This proposal will explore whether exhaustion, a common indicator of work strain, results from an accumulation of emotional demands and is part of the mechanism that underlies the relationship between emotional demands and alcohol use. I propose that exhaustion is the transmitting variable that can help explain why COs may engage in greater alcohol consumption (as measured by drink quantity on days when drinking and the frequency of these days) as a response to their emotional job demands.

Additionally, I propose that this process is conditional, meaning that under certain conditions, the association between exhaustion and alcohol use is stronger. Recovery experiences, that is, experiences during nonwork time that halt resource loss or help to build new resources (Sonnentag \& Fritz, 2007), are important moderators in the relationship between work demands and well-being and health outcomes (Siltaloppi, Kinnunen, \& Feldt, 2009; Sonnentag \& Fritz, 2015). At this time, little is known about how recovery experiences relate to alcohol use. However, it has been suggested that incomplete recovery, or lack of opportunities for employees to recover from their work demands, is a critical pathway to chronic health impairment (Geurts \& Sonnentag, 2006). Thus, this study seeks to address this important gap in the literature by investigating 
whether recovery experiences during nonwork time (i.e. mastery, relaxation, and psychological detachment) function as protective factors against work stress-related drinking. This study is the first to examine if recovery from work can reduce the positive association between work strain and alcohol use. A better understanding of specific work and nonwork conditions that contribute to employee alcohol use can help to develop future workplace interventions to reduce problematic forms of drinking. Additionally, this study answers the call for future research to examine additional moderators in the relationship between work demands, strain, and alcohol use (Frone, 2008; Frone, 2015). Failure to identify relevant moderators may contribute to more modest effect sizes as well as an inability to determine under which conditions researchers are likely to see a stronger effect. This knowledge can help develop more precise models around work stress-related drinking.

This study also contributes to past literature by focusing on a unique and understudied population, correctional officers (COs). While there is substantial research on work strain and health outcomes in general, limited research on these processes has been conducted within the corrections occupation. COs have the unique job of supervising individuals that have been deemed unfit to interact with the rest of society. Unsurprisingly, this type of work environment can create considerable strain for employees. According to the Bureau of Labor Statistics (2014), COs have one of the highest rates of occupational injury and illness, often as a result of encounters with inmates. Thus, it is of utmost importance that COs remain attentive and unimpaired while 
at work to ensure the safety of themselves, their coworkers, other inmates, and the general public. In addition, numerous psychosocial risk factors have been identified as potential contributors to strain in COs including high workload, lack of autonomy, underutilization of knowledge and skill, lack of job variety, role problems, health and safety risks, inadequate pay, poor social status, and demanding social contacts (Schaufeli, \& Peeters, 2000). Demanding social contacts refer to emotional demands placed on the officers from inmates, colleagues, and supervisors. Additionally, employees in this occupation have an increased risk of burnout, of which exhaustion is a key component, which refers to a long-term strain reaction common in employees that work with people as the main function of their job (Shaufeli \& Peeters, 2000). Thus, due to the emotionally demanding and exhausting nature of the job that COs perform within correctional facilities, they may have a greater risk for various health and strain related-problems like excessive alcohol consumption. In fact, one study reported that within their sample of COs, $11.1 \%$ reported drinking 15 or more drinks per week (Morse, Dussetschleger, Warren, \& Cherniack, 2011). This is particularly concerning given that this estimate is more than double the estimated $4.8 \%$ of the U.S. population that drink 15 or more drinks per week. Unfortunately, additional research on alcohol use among COs is incredibly limited, so this study seeks to address that gap.

In summary, this study explores whether work strain, specifically exhaustion, mediates the relationship between emotional job demands and alcohol use in correctional officers, and if greater levels of particular recovery experiences serve as a protective 
factor against work stress-related drinking, also referred to as drinking to cope motives. I will first give an overview of the literature on alcohol use including definitions and important known workplace outcomes. I will then discuss the theoretical frameworks relevant to the proposed model, specifically the job demands-resources model (JD-R; Demerouti, Bakker, Nachreiner, \& Schaufeli, 2001), the ego depletion model (Baumeister, Bratslavsky, Muraven, \& Tice, 1998), and conservation of resources theory (COR; Hobfoll, 1989). Finally, I will review past literature to support my proposed hypotheses.

\section{Alcohol Use}

Problematic drinking, or drinking more than moderate amounts of alcohol as defined by the National Institute on Alcohol Abuse and Alcoholism (NIAAA, 2004) as more than one drink a day for women and more than two drinks a day for men, represents a significant health concern for employers as well as for individuals. This is particularly true for those who engage in regular heavy or binge drinking. According to the NIAAA (2004) binge drinking refers to a pattern of drinking alcohol that corresponds to consuming five or more drinks for males, or four or more drinks for females in about two hours. However, other institutions often use different metrics for defining binge drinking such as JSAD's (2016) definition: drinking repeatedly for an extended period of time and giving up other usual activities. Heavy drinking refers to five or more drinks on the same occasion on each of five or more days in the past 30 days (NIAAA, 2004). Excessive drinking is associated with more health problems than moderate or light drinking, 
including alcohol poisoning, chronic diseases such as liver cirrhosis, pancreatitis, various cancers, high blood pressure, mental health issues such as anxiety and depression, social problems, unintentional injuries, violence, learning and memory problems, and alcohol abuse or dependence (Centers for Disease Control, 2014). Additionally, heavier drinkers tend to report more work performance problems than more light or moderate drinkers (Mangione, Howland, Amick, Cote, Lee, Bell, \& Levine, 1999). Recent prevalence estimates suggest that $74 \%$ of the workforce used alcohol within a 12 -month period with $31 \%$ drinking to intoxication, and $23 \%$ drinking to the point of a hangover (Frone, 2008). Drinking to the point of hangover or intoxication is especially relevant to organizational psychologists as the effects of drinking may spill over into the next workday impacting work outcomes such as attendance, task performance, and safety. While some employees may also drink before work or while at work, this study will focus on alcohol use that is assumed to be consumed during nonwork time.

\section{Workplace Outcomes of Alcohol Use}

It is essential that the factors that lead to employee alcohol use be examined due to the serious workplace consequences associated with alcohol involvement. Past research indicates a relationship between alcohol use and interpersonal problems at work. Ames and colleagues (1997) found that drinking at work and coming to work hungover (but not overall drinking) contributed to employee conflict with supervisors and coworkers. Another study found that heavier drinkers were more likely to argue with a coworker than more light or moderate drinkers and abstainers (Mangione et al., 1999). 
Past research also suggests a relationship between alcohol consumption and employee absenteeism. For example, one study found that while absenteeism was not related to same day drinking, it was related to prior day drinking such that employees who drank the night before a work shift were twice as likely to be absent the next day compared to those who did not drink that night (McFarlin \& Fals-Stewart, 2002). Another study found that heavier drinkers had an increased likelihood of short-term absenteeism (Cunradi, Griener, Ragland, \& Fisher, 2005). This represents a significant concern for employers due to the high costs associated with employee absenteeism including salary and fringe benefit costs as well as costs associated with lost productivity (Mirvis \& Lawler, 1977).

The link between alcohol use and occupational accidents and injuries has been unexamined thus far in corrections, but may be especially important due to the emphasis and potential consequences associated with safety in this occupation. While alcohol use has been linked to workplace accidents and injuries, the evidence is inconsistent. One study found that nondrinkers, light drinkers, and heavy drinkers all had elevated risks of workplace injuries, while moderate drinkers had a lower injury rate (Zwerling, Sprince, Wallace, Davis, Whitten, \& Heeringa, 1996). A more recent study reported that the relationship between substance use, which included both drugs and alcohol, and occupational injury was weak (Spicer, Miller \& Smith, 2003). Another reported that heavy drinkers were no more likely to report an injury on the job than abstainers (Mangione, et al., 1999). Thus, while the empirical relationship between alcohol use and 
occupational injuries is weak and inconclusive, popular belief maintains that alcohol use is a risk factor for workplace accidents and injuries possibly due to its impact on performance and physical functioning.

Past research has established that alcohol consumption is associated with impaired cognitive and motor functioning (Fillmore \& Vogel-Sprott, 2000) with greater performance detriments on tasks or processes that demand attention or effort (Holloway, 1994). Alcohol consumption has also been linked to general work performance problems such as self-reported problems performing the job, falling asleep on the job, problems with self-direction, conflict avoidance, and interpersonal relationships at work (Ames et al., 1997; Blum, Roman, \& Martin, 1993). In addition, alcohol use has been associated with lower levels of contextual performance, which may include less volunteering for additional tasks (Lehman \& Simpson, 1992), as well as higher levels of counterproductive work behaviors, such as the perpetration of aggressive or antagonistic behaviors toward coworkers (Ames et al., 1997; Lehman \& Simpson, 1992). Due to the myriad of adverse organizational consequences associated with employee alcohol use, it is essential to gain a better understanding of the predictors of alcohol use as well as what factors may contribute to decreases in drinking as a response to the work environment.

\section{Theoretical Background}

The theoretical framework for this study is drawn primarily from the job demands-resources model (JD-R: Demerouti, et al, 2001) and the ego depletion model (Baumeister et al., 1998), as well as conservation of resources theory (COR: Hobfoll, 
1989). The JD-R model proposes that burnout occurs as a result of two processes. First, continuous job demands lead to overtaxing and eventually, exhaustion. Second, a lack of resources further impedes meeting job demands, which leads to eventual disengagement (Demerouti et al., 2001). Exhaustion then can be thought of as a state that occurs due to prolonged work demands and may be exacerbated by a lack of available resources. This theory is used within the present study to link job demands and exhaustion, a previously established relationship.

The ego depletion model (EDM) will be the primary theoretical framework used to explain the proposed relationships with alcohol use and recovery experiences. EDM also focuses on resources and posits that volitional acts draw on a limited resource and that as it continues to be drawn on, it will impact subsequent volitional acts through a reduction in this limited resource (Baumeister et al., 1998). Volitional acts require selfcontrol so the limited resource being drawn on is likely self-regulatory resources. Dealing with demands draws on limited resources, over time leading to eventual exhaustion and adverse health outcomes. This theory helps explain how resources may impact the proposed relationships.

Additionally, COR theory will be drawn on as this theory suggests that individuals strive to maintain and gain resources (Hobfoll, 1989), which can help further explain the role of recovery in work stress-related drinking. Together, these theories use a resource perspective to explain how demands diminish resources contributing to exhaustion and increased drinking, but through high levels of recovery experiences, 
resources can be built to mitigate the impact of the demands and subsequent exhaustion on employee drinking.

\section{Hypothesis Development}

\section{Emotional Demands and Alcohol Use}

Workplace demands have received considerable attention as predictors of employee alcohol use, however the findings have been inconsistent, particularly at the between-person level. In a cross-sectional sample of young workers, Frone (2003) found that a variety of workplace stressors including low autonomy, job meaninglessness, distributive injustice, work demands, environmental hazards, and interpersonal conflict were not directly related to either overall alcohol use or on-the-job alcohol use. Similarly, Chen and Cunradi (2008) found that job hassles were not significantly directly or indirectly related to alcohol use at the between-person level. In a sample of blue-collar workers, Bacharach, Bamberger, and Sonnenstuhl (2002) found that role demands, conceptualized as 'work stress' were only weakly associated with alcohol use. Conversely, in a broad cross-sectional survey, several job demands have demonstrated direct associations, specifically work overload and job insecurity (Frone, 2008). However, these demands were only directly related to alcohol use before, during, after the workday and not to overall measures of alcohol use. Work-to-family conflict has also demonstrated a significant relationship with alcohol use at the between-person level (Frone, Russell, \& Cooper, 1993). Thus, while the cross-sectional literature is inconsistent regarding a direct link between most examined work demands and alcohol 
use, a focus on emotional demands, sometimes called high emotional load (Van Veldhoven and Meijman, 1994), and alcohol use has yet to be explicitly examined.

Due to the inconsistencies in the cross-sectional literature, a conditional variable may be unaccounted for. Past research on alcohol use suggests that negative affect (NA) may influence the association between stressors and drinking. If individuals drink alcohol in order to regulate their positive and negative emotions, as has been suggested by previous literature (Cooper et al., 1995), then affect plays an important role in drinking behaviors. While initially considered as a control variable, NA was retained as a substantive variable that may determine under what conditions COs are more likely to drink. Past research indicates that individuals who expect alcohol to relieve tension associated with stress are more likely to drink when experiencing stress and negative affect (Cooper, Russell, \& George, 1988). Armeli and colleagues (2000) found that men who believed drinking would result in a sense of carelessness were more likely to drink as a result of daily stress. This finding suggests that for these men, drinking is pursued to decrease self-awareness and attention, which may result in feeling less concerned about the stressful day one has had. Identifying who is most vulnerable to more problematic forms of alcohol consumption as a result of stress has been termed the stressor vulnerability model (Armeli et al., 2000). Further tests of this framework have established that those higher in NA are more likely to drink in the evening if they also believe that it will result in a sense of carelessness but less likely to drink in the evening if they believe that drinking will result in impairment (Armeli, DeHart, Tennen, Todd, \& 
Affleck, 2007). In addition, Armeli, Tennen, Affleck, and Kranzler (2000) found that daily NA as well as daily negative nonwork events predicted greater alcohol consumption, but that NA only weakly mediated the relationship between daily events and drinking. This finding may suggest that NA is not necessarily the reason why individuals drink in response to negative events, but rather it is an additional predictor that if present increases the likelihood that they drink in response to the negative event. Thus, I propose that negative affect will moderate the relationship between emotional demands and $\mathrm{CO}$ drinking.

Hypothesis 1: The relationship between emotional demands and both drinking quantity and drinking frequency will be moderated by negative affect, such that drinking and drinking more frequently, even under high levels of emotional demands.

\section{Emotional Demands and Exhaustion}

The JD-R categorizes characteristics of the work environment into either demands or resources and posits that they both contribute to independent psychological processes (Demerouti et al., 2001). Within this framework, job demands lead to eventual burnout, particularly the exhaustion component of burnout (Demerouti et al., 2001). Burnout, a common strain indicator, is considered to result from prolonged emotional load (Naisberg-Fennig, Fennig, Keinan, \& Elizur, 1991), where emotional demands eventually lead to strain without the necessary resources to effectively deal with them (Schaufeli \& Peeters, 2000). Exhaustion has been suggested to be at the core of burnout and refers to 
feelings of being depleted of one's emotional and physical resources (Maslach, Schaufeli, \& Leiter, 2001) and a consequence of prolonged affective, cognitive, and physical strain (Demerouti et al., 2003). Past research has demonstrated that emotional demands, in particular, do indeed predict exhaustion (Bakker, Demerouti, \& Euwema, 2005; Bakker, Demerouti, \& Schaufeli, 2003; Xanthopoulou, Bakker, Dollard, Demerouti, Schaufeli, Taris, \& Schreurs, 2007), therefore this hypothesis is a replication. Additionally, prolonged self-control efforts necessary when employees return to the same emotionally demanding job day after day may deplete self-regulatory resources over time (Muraven \& Baumeister, 2000). Considering past research and the capacity of emotional demands to drain both affective and regulatory resources, I propose that emotional demands will be positively related to exhaustion.

Hypothesis 2: Emotional demands will be positively associated with exhaustion.

\section{Exhaustion and Alcohol}

Exhaustion has been associated with a number of adverse outcomes for employees, including increased alcohol use. For instance, burnout, of which exhaustion is a main component, has been associated with an increase in alcohol and other substance use (Maslach, 1978). A more recent study also found an association between burnout and alcohol use; however, it is more strongly associated with alcohol dependency than alcohol-related harm (Cunradi et al., 2003). Similarly, a study comparing protective service occupations, such as corrections, found that while these employees do not consume alcohol more frequently than employees in other occupations they do report a 
higher occurrence of binge drinking and alcohol abuse or dependency (Weir, Stewart, \& Morris, 2012). These findings suggest that there is a relationship between employee burnout and alcohol use.

Burnout and its main component, exhaustion, are predicted by accumulated job demands (Bakker et al., 2007; Bakker, Demerouti, \& Verbeke, 2004; Demerouti et al., 2001). Dealing with excessive demands drains valuable resources, contributing to poor health behaviors such as excessive drinking and exhaustion. This may be because practicing health behaviors (such as limiting excessive drinking) requires resources, in particular self-regulatory resources. Theoretically, exhausted employees are thought to have a diminished supply of resources available once they reach this state, thus they may not have the means to self-regulate harmful health behaviors. This is in line with the EDM, which specifies that self-regulation acts like a muscle, and with overuse can grow tired (Baumeister et al., 1998). Additionally, past research indicates that individuals may drink to regulate their emotions, particularly to alleviate negative emotions and increase positive emotions (Cooper, Frone, Russell, \& Mudar, 1995). While this strategy may or may not be effective for actually regulating emotion, it still helps explain why some individuals are motivated to drink as a response to negative events and feelings. Thus, I propose that exhaustion will be positively related to alcohol use.

Hypothesis 3: Exhaustion will be positively associated with both drinking quantity and drinking frequency. 


\section{Exhaustion as a mediator}

Exhaustion may also be an important mediator between demands and other health and well-being outcomes. Specifically, emotional demands require employees to deal with situations that upset them emotionally which can deplete their emotional resources, eventually contributing to the experience of work strain and over time, exhaustion (Schaufeli \& Peeters, 2000). While there is also some support for the relationship between employee exhaustion and alcohol use, the association is not quite as clear due to the use of different types of measures and the focus on burnout as a whole instead of its different dimensions. Exhaustion may contribute to problematic drinking in the same way that emotional demands contribute to exhaustion, through depletion of valuable resources. Individuals have limited personal resources available to regulate behavior and deal with the demands of everyday life (Muraven \& Baumeister, 2000). When emotionally demanding jobs deplete an employee's emotional resources to the point of exhaustion, that employee then is in a state of diminished resources and may be vulnerable to various forms of maladaptive coping. With limited resources, the employee may then be more likely to drink alcohol due to the unavailability of self-regulatory resources, which could help to regulate drinking behaviors. This is in line with past research that found burnout fully mediated the relationship between job demands and health problems such as psychosomatic complaints (Schaufeli \& Bakker, 2004). Thus, I propose that exhaustion mediates the relationship between emotional demands and alcohol use. 
Hypothesis 4: The relationship between emotional demands and both drinking quantity and drinking frequency will be mediated by exhaustion.

\section{The Role of Recovery from Work}

Some prior research reports a direct relationship between work strain and alcohol use (Frone, 1999; Vasse, Nijhuis, \& Kok, 1998) suggesting that alcohol use may indeed result from exposure to work-related strain. However, more recent findings have challenged previous conclusions. Ng and Jeffrey (2003) found that perceived stress was not associated with frequency of alcohol use. Swatt, Gibson, and Piquero, (2007) found that work strain was not associated with either drinking prevalence or problematic alcohol consumption among a sample of police officers. In a sample of Finnish employees, the association between global job strain and heavy drinking was not significant (Kouvonen, Kivimäki, Cox, Poikolainen, Cox, \& Vahtera, 2005). Due to these inconsistent findings, there is an increasing focus on intervening variables, moderators, and temporally specific measures in the strain-alcohol relationship. For example, Frone (2008) found that work demands did not predict overall alcohol use, but did predict temporally specific measures of alcohol use, however this was a cross-sectional sample. Research has also investigated mediating effects of negative emotions and cognitions and found support for the mediating effects of distress (Wolff, Rospenda, Richman, Liu, \& Milner, 2013) and negative work rumination (Frone, 2015). Negative affect has also been examined as a mediator in the relationship between job stressors and strain and alcohol use, but the results are mixed (Frone, Barnes, \& Farrel, 1994; Cooper, Russell, \& Frone, 
1990). Numerous moderators have also been identified including workplace-drinking norms (Bacharach et al., 2002; Biron, Bamberger, \& Noyman, 2011), alcohol expectancies (Frone, 2015), peer drinking norms, coworker support, family support (Wang, Liu, Zhan, \& Shi, 2010), and escapist reasons for drinking (Grunberg, Moore, Anderson-Connolly, \& Greenberg, 1999; Grunberg, Moore, \& Greenberg, 1998). Butler, Dodge, and Faurote (2010) suggest that due to the inconsistent findings directly linking work-related strain and alcohol, there is potential for additional moderators that impact individuals' susceptibility to "stress induced drinking."

While infrequent moderate drinking as response to strain may not necessarily indicate a problem, falling in to patterns of drinking to cope with strain reinforces that maladaptive response and decreases the use of more adaptive coping mechanisms (Maisto, Carrey, \& Bradizza, 1999). One way to mitigate drinking as a response to work strain may be to provide opportunities for employees to recover from their work demands. Implicit in theoretical accounts of the relationship between stressors, strain, and alcohol are dynamic processes during which exposure to stressors and subsequent strain prompt strategies to cope with stressful circumstances and their associated negative affective states (Armeli, Todd, \& Mohr, 2005). Recovery from work refers to a process in which an individual's systems that are called upon while addressing work demands return to prestressor levels (Meijman \& Mulder, 1998), effectively allowing the individual to recover from or cope with demands of the day. Recovery experiences represent the psychological processes that are facilitated by activities that lead to eventual recovery of 
personal resources (Sonnentag \& Fritz, 2007). These resources refer specifically to psychological resources such as personal characteristics or energies (Hobfoll, 1989). There are several established types of recovery experiences and an infinite number of activities that employees may engage in during nonwork time that can facilitate these experiences. Sonnentag and Fritz (2007) suggested and validated four common recovery experiences that have been demonstrated to be beneficial for employee well-being.

\section{Recovery from work as a moderator}

This study focuses on three of these four recovery experiences, namely mastery, relaxation, and psychological detachment. I propose that these experiences are especially important in this study context because of their association with increases in positive affect (Fritz \& Sonnentag, 2006; Sonnentag \& Fritz, 2007) as well as their capacity to replenish self-regulatory resources. Regulatory resources are essential for the regulation of behaviors and emotions and may be especially relevant for regulation of health-related behaviors that may require some restraint.

When employees become exhausted, they may drink alcohol because they believe that drinking can help regulate their emotions, particularly by decreasing negative affect and increasing positive affect (Cooper et al., 1995). Indeed, mood is often assumed to be an indicator of processes closely linked to health-related outcomes (Stone, KennedyMoore, \& Neale, 1995). Mood repair can be considered a core function of recovery from work and several recovery experiences have been linked to increased positive mood, particularly relaxation, psychological detachment, and mastery (Fritz, Sonnentag, 
Spector, \& McInroe, 2010; Sonnentag \& Fritz, 2007). Past research supports the importance of changes in positive affect for health outcomes (Diener \& Emmons, 1984). Due to the positive association between recovery experiences and positive affect, employees may drink less when they have higher levels of recovery experiences as they may experience fewer negative emotions that they need to regulate.

Additionally, employees may drink as a response to exhaustion due to a lack of self-regulatory resources with which to resist drinking. However, if employees are high in recovery experiences, particularly relaxation and psychological detachment, these experiences may help build the resources needed to regulate behavior during nonwork time and resist drinking. The EDM (Baumeister et al., 1998) argues that the capacity for self-regulation resembles a muscle and may become worn out with extended use. Regulatory resources then can be built when regulation of behaviors or emotions is no longer necessary. Self-regulation is especially important when engaging in health behaviors that require some restraint or effort. Hofmann, Rauch, and Gawronski (2006) found that behaviors are predominantly influenced by more automatic attitudes when regulatory resources are low while when regulatory resources are high, personal restraint standards are a larger determinant of behavior. This study speaks to the importance of regulatory resources in determining behavior that may be somewhat automatic but requires some restraint such as drinking behaviors. Past research found that when individuals were required to regulate or suppress their thoughts, there was a marked decrease in control of alcohol consumption (Muraven, Collins, \& Neinhaus, 2002). 
Therefore, employees who engage in more recovery experiences may be less likely to drink as a response to exhaustion because they are able to recover emotional, regulatory, and other personal resources lost during the workday. The availability of these resources then limit the need to use alcohol to regulate emotions and strengthens their ability to regulate and potentially resist more problematic forms of drinking.

Individuals have limited resources available to regulate behavior and emotions (Muraven \& Baumeister, 2000), therefore rebuilding resources may serve as a protective factor against drinking as well as other forms of maladaptive coping. COR states that individuals seek to gain and maintain their resources, psychological or otherwise (Hobfall, 1989). Once employees have reached a state of exhaustion, where emotional, self-regulatory, and other personal resources are low, it may not be enough to simply halt the process of resource depletion. As employees shift into their nonwork time, they must find a way to stop resource loss and ideally build additional resources (Hobfall, 1989).

\section{Mastery as a moderator}

Mastery experiences refer to experiences during nonwork time that pose a challenge and provide learning opportunities, such as climbing a mountain or cooking a new recipe (Sonnentag \& Fritz, 2007). To engage in mastery, individuals must employ some level of self-regulation that requires an initial investment of self-regulatory resources. This initial investment can then support the accrual of more resources needed to protect against forms of maladaptive coping. Thus, mastery supports the recovery process by providing opportunities to build new resources like self-efficacy, positive 
affect, and vigor (Sonnentag \& Natter, 2004; Sonnentag \& Fritz, 2007; Sonnentag \& Grant, 2012). Prior research around alcohol use suggests that one reason individuals may drink is to rebuild emotional resources, particularly positive affect (Cooper et al., 1995). Research around mastery experiences suggests that these experiences can increase positive affect (Sonnentag, Binnewies, \& Mojza, 2008) and should theoretically increase other resources like self-efficacy and competence (Sonnentag \& Fritz, 2007). Therefore, if employees have high levels of mastery experiences, they may be building an arsenal of emotional resources that can serve as a protective factor against heavier drinking as result of work-related strain. Additionally past research found that mastery, conceptualized as a coping resource, was significantly and negatively related to drinking to cope motivation (Cooper, Russell, \& Frone, 1990). Therefore I propose that mastery experiences will moderate the relationship between employee exhaustion and alcohol use.

Hypothesis 5a: The relationship between exhaustion and both drinking quantity and drinking frequency will be moderated by mastery experiences, such that employees reporting high levels of mastery will report drinking less when drinking and drinking less frequently, even under high levels of exhaustion.

\section{Relaxation as a moderator}

Relaxation during nonwork time refers to a state of low activation associated with increased positive affect, few social demands, and little required effort (Sonnentag \& Fritz, 2007). Additionally, resources acquired as a result of engaging in relaxing activities may manifest as decreased levels of burnout and psychosomatic health complaints (Fritz 
\& Sonnentag, 2006). Positive affect can be considered an emotional resource gained through the experience of relaxation. Additionally, relaxing experiences may also have the capacity to build regulatory resources, due to the low effort nature of the experiences. Again, drawing on the EDM (Baumeister et al., 1998), relaxing activities may provide the 'rest' the regulatory muscle needs to return to its full capacity and replenish regulatory resources. Therefore relaxation during nonwork time may allow building necessary emotional and self-regulatory resources that can serve as a protective factor against heavy drinking as result of work-related strain. Therefore I propose that relaxation experiences will moderate the relationship between employee exhaustion and alcohol use.

Hypothesis 5b: The relationship between exhaustion and both drinking quantity and drinking frequency will be moderated by relaxation experiences, such that employees reporting high levels of relaxation will report drinking less when drinking and drinking less frequently, even under high levels of exhaustion.

\section{Psychological Detachment from Work as a Moderator}

Psychological detachment refers to a sense of being away from work by disengaging mentally from work, not being occupied by work demands during nonwork time, not engaging in work tasks while not at work, and not ruminating about work problems or opportunities (Sonnentag \& Fritz, 2007). Detachment typically does not require self-regulation, unless the individual has to actively try to detach and avoid thoughts about work (Sonnentag \& Bayer). Because detachment provides the opportunity to distance oneself from work demands that do require regulation, this experience often 
provides the opportunity to rebuild regulatory resources by engaging in activities that no longer tax those same resources (Baumeister et al., 1998).

In addition, psychological detachment may also increase affective or emotional resources, however the evidence is mixed. Totterdell and Parkinson (1999) found that detachment or distraction was an effective mood regulation strategy for improving affect. Other research has found that greater detachment during nonwork time was associated with increases in positive affect and decreases in negative affect (Sonnentag, Mojza, Binnewies, \& Scholl, 2008), while some reported that detachment predicted only two of the three positive affective states, specifically joviality and serenity (Fritz, Sonnentag, Spector, \& McInroe, 2010). It is likely that detachment influences mood and resource accrual in different ways for different individuals, which may help explain past inconsistencies. Therefore I propose that psychological detachment will moderate the relationship between employee exhaustion and alcohol use.

Hypothesis 5c: The relationship between exhaustion and both drinking quantity and drinking frequency will be moderated by psychological detachment, such that employees reporting high levels of detachment will report drinking less when drinking and drinking less frequently, even under high levels of exhaustion.

\section{Research Question 1: A Moderated Mediation Model}

In addition to the above hypotheses, I also examined several research questions.

First, I tested a second-stage moderated mediation model based on the framework set forth by Preacher, Rucker, and Hayes (2007). This type of model attempts to explain both 
how and when a given effect occurs (Frone, 1999), and is often used when the mediation proposed is contingent on the moderator, in this case recovery experiences. Recovery experiences may not only impact the indirect relationship between exhaustion and alcohol use, but also the strength of this indirect effect. Therefore, a moderated mediation model was tested to examine if there was a significant conditional indirect effect.

Research Question la-c: Do the recovery experiences mastery (Research Question 1a), relaxation (Research Question 1b) and psychological detachment (Research Question 1c) moderate the strength of the mediated relationship between emotional demands and both drinking quantity and drinking frequency via exhaustion, such that the mediated relationship will be weaker under high levels of recovery experiences?

\section{Research Question 2: Nonwork Control, Exhaustion, \& Alcohol}

A sense of personal control can influence health both directly and as a stress buffer (Thoits, 1995). Nonwork control experiences refer to a sense of being able to choose which activities to pursue during nonwork time and how and when to pursue them (Sonnentag \& Fritz, 2007). Control experiences also support the recovery process by providing opportunities to gain new resources, particularly autonomy, self-efficacy, and potentially positive affect (Sonnentag \& Fritz, 2007; Larson, 1989). Nonwork control was not included in the hypotheses because it is unclear what role nonwork control plays in the relationship between strain and alcohol use. One paper suggests that control experiences have the potential to restore affective and regulatory resources because they 
allow for individuals to pick activities that best suit them and to not choose activities that contribute to strain, thus facilitating restoration of affective and regulatory resources (Hahn, Binnewies, Sonnentag, \& Mojza, 2011). However, this paper did not actually test this proposition therefore, it is difficult to determine how control experiences will interact with exhaustion to predict alcohol use.

In addition, control is strongly associated with autonomy, which refers to "an inner endorsement of one's own actions" (Deci \& Ryan, 1987, p. 1024), or more simply, perceived personal control, often within the work domain. Nonwork control experiences offer the opportunity to build autonomy because individuals are able to pursue the activities they want to pursue outside of work. Autonomy may increase positive affect and thus emotional resources, however some past research has found that autonomy is positively related to adolescent alcohol use, though it is unclear if this association holds true for adults (Staff \& Uggen, 2003). Conversely, feelings of powerlessness, that may be associated with a lack of control, have been associated with both heavy and problem drinking (Seeman and Anderson, 1983). So, in assessing these findings it is unclear how nonwork control will relate to alcohol use.

Research Question 2: Do nonwork control experiences moderate the relationship between exhaustion and employee drinking quantity and drinking frequency?

\section{Research Question 3: Direct Relationships Between Drinking and Recovery}

Both alcohol use and recovery from work may represent strategies employees engage in to cope with and manage daily demands and emotions. At this time, little is 
known about how recovery experiences directly relate to alcohol use, however older drinking motives scales indicate that these constructs may be closely intertwined. Both ‘drinking for personal effects' (Mulford \& Miller, 1960) and 'escapist reasons for drinking' (Grunberg, Moore, Anderson-Connolly, \& Greenberg, 1999) include drinking to relax and drinking to forget about work (detachment). This construct has also been referred to as 'drinking to cope' and aligns closely with the goals of recovery experiences such as to forget about stressors (detachment), to relax (relaxation), and to cheer oneself up (Cooper, Russell, Skinner, \& Windell, 1992). It is possible that for some employees, drinking alcohol (in light to moderate doses) may be an activity that helps facilitate certain recovery experiences. Two experiences potentially involved in this process are psychological detachment from work and relaxation. The appraisal disruption model (Sayette, 1993) of stress and alcohol suggests that alcohol use can disrupt information processing and appraisal of new information protecting the drinker from fully experiencing the stressor, thus facilitating detachment from that stressor. Armeli and colleagues (2005) add that some individuals may drink in order to become less aware of or concerned with stressors. Thus, it is possible that individuals may drink alcohol in order to facilitate the experience of psychological detachment from work. Additionally, a commonly reported reason for drinking is to 'relax'. Armeli and colleagues (2003) report that alcohol consumption positively predicts evening relaxation and happiness. So while unable to test causal relationships due to the study design, this research question seeks to 
examine the between-person associations between drinking behaviors and relaxation and detachment.

Research Question 3a-b: Are drinking quantity and drinking frequency positively associated with the recovery experiences relaxation (Research Question 3a) and psychological detachment from work (Research Question 3b)? 


\section{Method}

\section{Participants and procedure}

Correctional officers (COs) were recruited from all 14 state correctional facilities in Oregon. Officers received an email inviting them to participate in a survey examining work strain among correctional officers. The email included a link to the online survey, as well as instructions to request a paper copy if preferred. The email and subsequent reminder emails were sent by researchers at Portland State University as well as by the superintendent of each facility to their respective facility, a labor union representative, and a member of the State's department of corrections research department. Data collection was staggered by facility over several months. Once the invitations for a particular set of facilities were sent, officers had two weeks to complete the survey. For officers that participated via the online link, their responses were sent directly to the researchers. Officers that requested paper copies returned their survey via a prepaid return envelope sent through the mail. All survey responses were anonymous.

At the time of data collection, there were 2,461 COs employed by the state. The initial sample consisted of 1,370 participants for a response rate of 54\%. Of this group, 39 respondents were excluded for indicating that they did not work as security staff, meaning they did not hold the title correctional officer, corporal, sergeant, lieutenant, or captain. Another 14 respondents were excluded for indicating that they worked in the transport unit, because these employees are not actually within the facility day to day and may have different job demands and experiences. 
Nondrinkers were also excluded from the analyses in order to focus on COs that do drink at least one day out of a month. Nondrinkers are unlikely to use alcohol to cope with work strain but most certainly experience work strain so their inclusion would attenuate the predicted effects (Cooper, Russell, \& Frone, 1990). Therefore, participants that indicated that they drink zero days out of a month were excluded $(N=278 ; 21 \%$ of the sample). While this percentage of nondrinkers is particularly low compared to the national estimate (somewhere between 36-58\%; SAMHSA, 2014), our actual proportion of nondrinkers may be closer to the lower bound of that estimate considering that some COs did not respond to the alcohol items. Overall, about 64\% reported drinking the past month, $21 \%$ reported not drinking at all in the past month, and about $15 \%$ is unaccounted for. Descriptive analyses compared the full sample to the subset to determine if there were any major differences. Both groups appear to be almost identical on key study variables with the exception of the two alcohol use variables. The subset that excluded the nondrinkers reported drinking more drinks on average when drinking and drinking more often through the course of a month. These exclusions brought the total sample size to $N=1,039$. While the subset is what the remainder of this paper will focus on, all hypothesis tests were also conducted using the full sample and those results are available upon request. For surveys that were incomplete (e.g. missing data), listwise deletion was employed where appropriate. Therefore, the sample size for each analysis varied, depending on how many COs responded to the items for the variables included in the analysis. 
Participating COs were predominantly Caucasian (84\%) and male (83\%). The majority was married (71\%) and about half (53\%) reported some college experience, however only $28 \%$ actually held a college degree of some kind. Officers worked within a range of security levels including minimum (30\%), medium (51\%), and maximum security (19\%). They worked 42.84 (SD 6.22) hours per week on average in a variety of different work shifts with the majority working day shifts (around 45\%) followed by swing shifts (around 35\%), and the night shift (around 21\%). Officers reported working in corrections for 11.91 (SD 7.03) years on average and working in their current facility for 9.19 (SD 6.37) years. With regard to alcohol use, there was a range of responses indicating sufficient variability in officer drinking. While all officers included in these analyses reported drinking alcohol at least one day a month, 29\% reported drinking 10 days a month or more, and six percent reported drinking every day. Additionally, $13 \%$ of officers reported drinking five or more drinks per day on days when drinking. These estimates indicate that there is a concerning amount of heavy drinking occurring within corrections. See Figure 2 for a breakdown of average drinks per day on days when drinking.

\section{Measures}

All measures asked respondents to consider the past month as the timeframe when answering the survey questions. For a full list of items please refer to Table 1.

Emotional Demands. The English version of the emotional workload subscale of the 'Variety in Your Work Scale: Dutch Questionnaire on the Experience and Assessment 
of Work' (VBBA; Van Veldhoven \& Meijman, 1994) was used to assess emotional demands. This subscale consists of three items on a 5-point rating scale ranging from 1 (Very rarely or never) to 5 (Several times an hour). Sample items include "Did your work put you in emotionally upsetting situations?" and "Did your work demand a lot from you emotionally?" Cronbach's alpha for the scale was .90 .

Exhaustion. The exhaustion subscale of the Oldenburg Burnout Inventory (OLBI; Demerouti, Bakker, Vardakou, \& Kantas, 2003) was used to assess employee exhaustion. This subscale consists of eight items on a 5-point rating scale ranging from 1 (Not at all) to 5 (Very much). Sample items include "During my work, I often felt emotionally drained" and "After my work, I usually felt worn out and weary". Cronbach's alpha for the scale was .85. For this subscale, four items have been reversecoded.

Alcohol Use. Alcohol consumption over the past month was assessed with two independent items. Self-reported frequency of drinking was assessed with the single item 'On how many days did you consume alcohol?' Quantity was assessed with the single item 'When you did drink, how many drinks did you have in a day?' Participants were instructed that one drink referred to either $12 \mathrm{oz}$ of beer, $5 \mathrm{oz}$ of wine, or $1.5 \mathrm{oz}$ of liquor (NIAAA, 2004). For each of these questions, participants were prompted to write in their response.

Recovery Experiences. The Recovery Experience Questionnaire (REQ; Sonnentag \& Fritz, 2007) was used to measure mastery, nonwork control, relaxation, and 
psychological detachment experiences during nonwork time. Each subscale of the REQ consists of four items on a 5-point rating scale, ranging from 1 (Not at all) to 5 (Very much). A sample item from the mastery scale was "I sought out mental challenges". Cronbach's alpha for the subscale was .86. A sample item from the control scale was "I determined for myself how I spent my time". Cronbach's alpha for the scale was .85. A sample item from the relaxation scale was "I kicked back and relaxed." Cronbach's alpha for the scale was .91. A sample item from the psychological detachment scale was "I forgot about my work." Cronbach's alpha for the scale was .74. A confirmatory factor analysis was conducted to evaluate whether a four-factor model is most appropriate considering the high correlations between the four recovery experience subscales (see Table 2). Analysis results indicate adequate fit to the data, $\chi^{2}(98)=879.72, p<.001$, CFI $=.91, \mathrm{RMSEA}=.10$. Compared to one, two, and three factor models of recovery experiences, the four-factor model provides the best fit providing support that these four experiences are distinguishable constructs.

Negative Affect. Trait negative affect was measured with 10 items from Watson and Clark (1999) on a 5-point scale ranging from 1 (Never) to 5 (Always). This scale asked to what extent participants experienced a variety of moods such as 'upset' or 'ashamed'. Cronbach's alpha for this scale was .86 .

Control Variables. I included the control variables participant gender, age, and work shift. Past research indicates that alcohol use differs between individuals based on a number of demographic variables. For instance, women are less likely to drink alcohol in 
response to strain than men (Pohorecky, 1991) and men with positive alcohol expectancies drink more heavily and experience more alcohol problems than women with positive alcohol expectancies (Cooper, Russell, Skinner, Frone, \& Mudar, 1992). Second, alcohol use has been shown to vary by age. Younger individuals and college students may drink more and more frequently than older individuals, particularly during emerging adulthood (SAMHSA, 2014). Additionally, younger individuals may endorse different motives for drinking relative to their older counterparts (Maisto, Carrey, \& Bradizza, 1999). Finally, shiftwork may influence alcohol use as well as experiences of work strain. While I was unable to find literature that cites any direct relationships between shift work and drinking, past empirical work has definitively determined that shift work disrupts employee sleep and nonwork life leading to increases in fatigue, work-life conflict, mental health disorders like anxiety and depression, and physical health problems like cardiovascular and gastrointestinal issues (Harrington, 2001). Considering the widespread impact that shiftwork appears to have on all aspects of employee life, it is likely that drinking behaviors and motives are also impacted. In addition, all of the above control variables were significantly correlated with one of the dependent variables, which is recommended to maximize power (Becker, 2005). In the case of both age and gender, there were also significant group differences in both drinking frequency and drinking quantity. Despite these significant group differences, I believe that based on the literature cited above, these are biasing factors as opposed to substantive ones. 
Security level was considered as additional control variable, but was not included in the hypothesis testing. While working in a maximum security as opposed to a minimum security facility likely has different stressors, security level did not demonstrate any significant group differences on any of the key variables in this study. Additionally, it was not significantly correlated with any of the outcome variables. Therefore, security level was not retained as a control variable.

\section{Results}

\section{Preliminary Analysis}

All analyses were conducted both with and without three potential identified outliers within the drinking frequency and quantity variables. The reported results include all data values because the overall pattern of hypothesized results remained the same both with and without the inclusion of the identified outliers. Considering that drinking quantities and frequencies can have considerable variability, from a practical standpoint I believe it makes sense to include all possible values to ensure that we have a complete picture of $\mathrm{CO}$ drinking behavior. Thus, all data points were retained for the reported results.

Descriptive statistics showed that the mean frequency of alcohol consumption per month was 7.72 days $(S D=8.36)$, mean average drinks per day on days when drinking were 3.01 drinks $(S D=2.33)$. In addition, gender differences on the alcohol use variables were also examined based on past research that indicates that there are significant gender differences in drinking (Holmila \& Raitsalo, 2005). Among the drinkers, descriptive 
analyses indicate that men drink significantly more than women when drinking, and while not significant men also drank more frequently. These findings are in line with what we would expect to see with regard to gender differences in alcohol use. However, overall mean reports of alcohol use are not broken down by gender within the document due to the low proportion of women within our sample. Intercorrelations and additional descriptive statistics can be found in Table 2. Tests for the assumptions of multilevel modeling were conducted to see if the data should be analyzed as nested data. Intraclass correlation coefficient (ICC) values were calculated to determine if alcohol use is dependent on group membership (i.e., by correctional facility). The values were at or near zero, indicating that it was not necessary to nest the data (Bliese \& Jex, 2002) and that it is unlikely that $\mathrm{CO}$ drinking varies systematically by facility.

Drink quantity is considered a count or frequency variable meaning that it reflects a number of events in a given period of time. When using a count variable with a low mean as an outcome, Poisson regression should be used in order to reduce the potential for biased results (Coxe, West, \& Aiken, 2009). Poisson regression is useful for distributions that are heavily skewed and where the majority of the counts are close to zero. While drinking frequency is technically not considered a count variable, it also demonstrated a Poisson shaped distribution with a heavy skew to the right. In order to account for the nonnormal distribution of the outcome variables, bias corrected bootstrapping (5000) within PROCESS (Hayes, 2013) was utilized. Hayes (2013) recommends at least 5000 samples for use in scientific publications. 


\section{Hypothesis Testing}

All of the following hypothesis tests include the covariates age, gender, and work shift in the model. All products were grand mean centered. Hypothesis 1 proposed that negative affect would moderate the relationship between emotional demands and both drinking quantity and drinking frequency. To test this, two moderation models were specified in PROCESS, one for each drinking outcome. Results indicate that there was not a significant interaction effect of negative affect and emotional demands on either drinking quantity $(b=-.09, p=.58)$ or drinking frequency $(b=-.78, p=.21)$, thus Hypothesis 1 was not supported. To test Hypotheses 2-4, two mediation models were specified with emotional demands as the predictor, exhaustion as the mediator, and either drinking quantity or drinking frequency as the outcome. Emotional demands did significantly predict employee exhaustion $(b=.40, p<.001)$, providing support for Hypothesis 2. In addition, employee exhaustion significantly predicted both drinking quantity $(b=.35, p=.03)$ and drinking frequency $(b=1.30, p=.03)$, supporting Hypothesis 3. A test of the indirect effect of emotional demands on drinking revealed a significant indirect effect of emotional demands on both drinking quantity (indirect effect $=.14 ; 95 \%$ BC CI: [.02-.27]) and drinking frequency (indirect effect $=.52 ; 95 \%$ BC CI: [.07-1.00]) through employee exhaustion, providing support for Hypothesis 4. These results suggest that for COs, high emotional demands contribute to drinking at least partially through experiences of exhaustion. 
To test Hypothesis 5a-c, which proposed recovery experiences would moderate the relationship between exhaustion and drinking, six moderation models were specified in PROCESS. Drinking quantity and drinking frequency were regressed on the interactions between exhaustion and the recovery experiences mastery (H5a), relaxation (H5b), and detachment (H5c). Results indicate that there was not a significant interaction effect of mastery and exhaustion on either drinking quantity $(b=-.08, p=.45)$ or drinking frequency ( $b=-.67, p=.14)$, thus Hypothesis 5 a was not supported. However, there was a significant interaction effect for relaxation and exhaustion on drinking quantity $(b=-.24$, $p=.04)$, but not drinking frequency $(b=-.69, p=.20)$, providing partial support for Hypothesis $5 b$. Similarly, there was a significant interaction effect for psychological detachment and exhaustion on drinking quantity $(b=-.26, p=.03)$ but not drinking frequency $(b=-.33, p=.60)$ providing partial support for Hypothesis $5 \mathrm{c}$. These results suggest that COs who report more exhaustion also report drinking more drinks on days when drinking particularly if they are low in experiences of relaxation and psychological detachment. However, levels of detachment and relaxation do not significantly impact drinking frequency. In addition, mastery experiences do not interact with exhaustion to influence any examined drinking behaviors. Graphical displays of the significant interaction effects can be found in Figures 5-6.

\section{Research Question 1}

Research Question 1 investigated whether recovery experiences moderate the indirect effect of emotional demands on drinking through employee exhaustion. 
PROCESS was again utilized as this program allows for a more streamlined approach to moderated mediation. Moderated mediation is a type of conditional process model that can help determine whether emotional demands predict drinking indirectly through exhaustion depending on the level or amount of reported recovery experiences. The test of second stage moderated mediation with 5000 bias-corrected bootstrapped samples revealed a conditional indirect effect for relaxation on $\mathrm{CO}$ drinking quantity (indirect effect $=-.09,95 \%$ BC CI: [-.190- -.004]), but not drinking frequency (indirect effect $=$ $.27,95 \%$ BC CI: [-.693-.125]). This suggests that when COs experience high levels of emotional demands, it contributes to feelings of exhaustion which then results in drinking more drinks on days when drinking, unless they are also high in relaxation experiences. Similarly, there was also a significant conditional indirect effect for psychological detachment on drinking quantity (indirect effect $=-.10,95 \%$ BC CI: [-.197- -.003]) but again, this was not observed for drinking frequency (indirect effect $=-.10,95 \%$ BC CI: [$.601-.383])$. Therefore, COs that tend to detach less are more likely to drink more on days when drinking when they experience high levels of exhaustion as a result of their emotional job demands. For mastery experiences, the conditional indirect effect was not significantly different from zero for either drinking quantity (indirect effect $=-.02,95 \%$ BC CI: [-.118-.062]) or drinking frequency (indirect effect $=-.24,95 \%$ BC CI: [-.620.087]). This pattern of relationships aligns closely with the above results. It appears that relaxation and detachment work as 'buffers' against greater alcohol consumption as a 
result of this stress-related drinking process, while mastery does not have a similar protective influence.

\section{Research Question 2}

Research Question 2 examined an additional moderator, the recovery experience of nonwork control, between employee exhaustion and drinking behaviors. To investigate the role of this additional recovery experience, the same steps utilized for analyzing Hypothesis 5 were followed, using nonwork control and exhaustion as the predictors of CO drinking in a moderation model within PROCESS. Results indicate that there was not a significant interaction effect of control and exhaustion on either drinking quantity $(b=-$ $.17, p=.20)$ or drinking frequency $(b=-.58, p=.34)$, thus Research Question 2 was not empirically supported.

\section{Research Question 3}

Finally, Research Question 3 sought to investigate the direct relationships between $\mathrm{CO}$ drinking behaviors and the recovery experiences detachment and relaxation. Several regression models were tested using OLS regression in SPSS using the subset of COs that drink at least one day in a typical month. For this analysis control variables were not included to get a broad picture of what the basic between-person associations are within the dataset. Correlations between drinking quantity, drinking frequency, relaxation, and detachment were all statistically significant at the .001 level, however they were not especially large effects, see Table 2 for specific values. Results of the regression analysis indicate that drinking quantity is significantly negatively related to 
relaxation $(b=-.075, p<.001)$ suggesting that COs who tend to drink more on days when drinking also tend to report less relaxation in general. Drinking frequency was also significantly negatively related to relaxation $(b=-.019, p<.001)$, suggesting that those who drink more frequently also tend to report less relaxation. Results with regard to detachment follow the same pattern. Drinking quantity was negatively related to detachment $(b=-.061, p=.001)$ as was drinking frequency $(b=-.011, p=.026)$. COs that tend to drink more on days when drinking and that drink more frequently also tend to report less detachment in general. However, the negative associations are weaker for detachment than for relaxation. Overall, these findings do not support a positive association between drinking and recovery experiences at the between person level, however this association should be tested at the day level to determine if they may actually co-occur. There is evidence that suggests that relationships between drinking its antecedents and consequences look different at the between vs. the within-person level (Carney, Armeli, Tennen, Affleck, \& O’Neil, 2000; Frone, 2013).

\section{Additional Analyses}

In addition to the above analyses, several additional models were tested in PROCESS using the same covariates. After finding partial support for a second stage moderated mediation model, a first stage moderated mediation model was also tested including the recovery experiences as moderators between emotional demands and employee exhaustion. Occupational health psychology emphasizes focusing intervention efforts further upstream as opposed to further downstream in order to prevent problems 
before they occur rather than addressing them once they become bigger problems. Thus, determining whether recovery experiences buffer the impact of emotional demands on exhaustion can help to inform intervention efforts aimed at reducing drinking prior to employees becoming exhausted. Results indicate that there was no significant conditional indirect effect for any of the recovery experiences.

Taking a step back from conditional process analysis, recovery experiences were also examined as potential moderators between emotional demands and exhaustion. Past research indicates that recovery experiences may buffer the impact of job demands on job strain (Sonnentag \& Fritz, 2015). However, there were no significant interaction effects detected. For due diligence, the recovery experiences were also examined as moderators between emotional demands and both drinking outcomes. Results indicate a significant interaction effect for detachment and emotional demands on drinking quantity only ( $b=$ $.22, p=.02)$, not drinking frequency. This finding may suggest that COs high in emotional demands that are also high in psychological detachment will report drinking less on days when drinking than those reporting less psychological detachment. No other significant interactions were detected.

Exhaustion on its own is a common indicator of work strain, but when it occurs in concert with employee disengagement, that employee is considered to be 'burnt out'. Burnout occurs when job demands are high and employees do not have enough resources to deal with their accumulated demands (Demerouti et al., 2001). Recovery experiences may provide the resources needed to handle the emotional job demands experienced 
within the corrections occupation. Considering that the exhaustion component was already examined, employee disengagement was assessed as an additional mediator between emotional demands and alcohol use. Disengagement refers to distancing oneself from work and often involves employees endorsing negative attitudes toward their work and demonstrating decreased willingness to continue working in the same occupation (Demerouti \& Bakker, 2008). This was measured with an additional eight items from the Oldenburg Burnout Inventory (OLBI; Demerouti, Bakker, Vardakou, \& Kantas, 2003) on a 5-point rating scale ranging from 1 (Not at all) to 5 (Very much). Results indicate that emotional demands did significantly predict employee disengagement $(b=.08, p<.001)$ and disengagement significantly predicted drinking frequency $(b=2.22, p<.001)$, but not drinking quantity $(b=.21, p=.17)$. A test of the indirect effect of emotional demands on drinking behaviors revealed a significant indirect effect of emotional demands on drinking frequency (indirect effect $=.41 ; 95 \%$ BC CI: [.179-.730]) through employee disengagement. Therefore, emotional demands seem to impact how frequently COs drink by contributing to feelings of disengagement. COs who report high levels of disengagement also report that they drink more frequently than coworkers who report less disengagement from their jobs. However, there was not a significant indirect effect of emotional demands on drinking quantity through disengagement (indirect effect $=.04$; 95\% BC CI: [-.015-.096]). These findings taken together suggest that while exhaustion plays a large role in the prediction of both how often employees' drink and how much 
they drink when they are drinking, disengagement is only useful in predicting drinking frequency.

Recovery experiences were also examined as moderators between disengagement and $\mathrm{CO}$ drinking to determine if recovery experiences can buffer the impact of disengagement on $\mathrm{CO}$ drinking behaviors. Results of these analyses found that of the four examined recovery experiences, only disengagement and mastery experiences had a significant interaction effect on drinking frequency $(b=-1.12, p=.03)$, though nonwork control experiences had a marginally significant effect $(b=-1.06, p=.07)$. No significant interaction effects were detected for drinking quantity. These findings suggest that COs high in disengagement are less likely to drink more frequently if they also report being high in mastery experiences and experiences of nonwork control. This pattern of results is in stark contrast to what was found for employee exhaustion. Implications of these findings will be discussed in the discussion section. 


\section{Discussion}

\section{Contributions}

This study sought to examine a potential pathway through which job demands within the corrections occupation contribute to increased alcohol consumption, as well as a potential protective mechanism against this kind of work-stress related drinking. Considering that COs have been identified as an occupational group that tends to engage in much higher rates of problematic drinking compared to the general population (Morse et al., 2011), it is important for researchers to identify what aspects of the corrections environment contribute to these elevated drinking levels as well as ways to potentially mitigate their influences.

This study contributes to current literature by providing empirical support for the positive associations between emotional job demands, burnout, and drinking behaviors in corrections. Results indicated that emotional demands did not have a significant main effect on either $\mathrm{CO}$ drinking quantity or frequency or a significant interaction effect with negative affect on either drinking outcome. This finding points to the importance of intervening variables in the relationship between job demands and drinking. Job demands on their own or in concert with high levels of negative affect may not be enough to influence drinking behaviors, however, when demands lead to strain reactions, the picture that emerges is much different. This study found that emotional job demands positively predicted employee exhaustion, a common strain reaction and main component of employee burnout, and that exhaustion significantly and positively predicted both 
drinking quantity and drinking frequency. These findings are in line with a resource perspective in which job demands contribute to strain and poor health and well-being outcomes as they accumulate. Thus, while demands are insufficient in predicting drinking behaviors, strain is not. In addition, exhaustion partially mediated the relationship between emotional demands and both drinking quantity and drinking frequency providing further evidence for the role of the work environment in employee drinking. Therefore, when COs experience high levels of emotional demands, these demands contribute to exhaustion which then predicts increases in the amount of drinks consumed and the frequency with which they are consumed.

Additionally, this study was the first to examine if recovery from work experiences can reduce the positive association between work strain and alcohol use. Demands diminish resources contributing to exhaustion and increased drinking, unless additional resources can be built or replenished to mitigate the impact of the demands and subsequent exhaustion on employee drinking. Findings indicate that while mastery did not interact with exhaustion to predict either drinking outcome, both detachment and relaxation did demonstrate significant interaction effects on drinking quantity, but not drinking frequency. Thus, certain recovery experiences, specifically detachment and relaxation, may serve a protective function against more problematic or excessive forms of work stress-related drinking. Recovery experiences had not yet been examined as a moderator in the work strain and alcohol relationship, therefore this study answered the call for examination of additional moderators to help better identify under what 
conditions the work environment leads some employees to drink but not others (Frone, 2015).

In addition to these piece-meal findings, this study found evidence for a significant conditional indirect effect for several of the recovery experiences on drinking quantity. Specifically, detachment and relaxation moderated the strength of the indirect effect of emotional demands on drinking quantity through exhaustion, suggesting that COs that tend to relax and detach less are more likely to drink more drinks when they are experiencing high emotional demands that lead to exhaustion. This is important as it demonstrates that recovery experiences are not only useful in diminishing the strength of the positive association between exhaustion and drinking quantity, but also impact the process through which emotional demands contribute to drinking. No significant effects were found for drinking frequency, suggesting that as indicated above, recovery experiences are a protective influence against the amount of drinks consumed when drinking, but not how often drinking occurs.

The additional recovery experience of nonwork control was also examined as a moderator in the relationship between exhaustion and $\mathrm{CO}$ drinking. Results indicate that control experiences did not interact with exhaustion to significantly predict either drinking outcome. This is in line with past research that finds control is often the least predictive of the main recovery experiences (Fritz, Sonnentag, Spector, \& McInroe, 2010). This finding suggests that feeling in control of time outside of work does not influence work stress-related drinking, particularly drinking as a result of exhaustion. 
A final research question investigated the general associations between detachment and relaxation and both drinking quantity and frequency. Considering that associations between recovery from work and alcohol use have not yet been explicitly examined, this was a first step in understanding the general relationships between these two constructs. Results indicate that both drinking quantity and drinking frequency were significantly negatively related to both detachment and relaxation. This finding makes sense within the context of this model, whereby recovery experiences buffer against greater levels of drinking, suggesting a negative relationship. However, when considering the drinking to cope construct we might expect that those drinking to cope with high levels of work strain and exhaustion drink to avoid thinking about work and to relax (Cooper et al., 1995). However, we see that that is not the case at the between-person level. Those who tend to drink more and more often also tend to report less psychological detachment from work and relaxation experiences because alcohol may be exacerbating negative feelings. These associations should be more thoroughly examined using a more appropriate measurement design.

Several additional analyses were also conducted in order to better understand the interrelationships of the examined variables. The recovery experiences were examined as moderators between emotional demands and drinking, as well as between demands and exhaustion. Recovery experiences do not appear to significantly moderate the relationship between emotional demands and exhaustion. This is somewhat surprising considering that past research has established the importance of recovery from work as a 
buffer in the stressor-strain relationship (Sonnentag \& Fritz, 2015). In addition, recovery experiences also do not significantly moderate the relationship between demands and either drinking outcome with one exception. Emotional demands and detachment did significantly interact to negatively predict drinking quantity. This might suggest that COs consume less drinks when they are high in emotional demands and also high in detachment. Overall the relationships between the recovery experiences, exhaustion, and drinking only appear to impact drinking quantity and not drinking frequency.

An additional mediator, employee disengagement, was examined to determine if burnout actually mediates the relationship between emotional demands and alcohol use, rather than work strain. Results reveal that emotional demands are positively related to disengagement and that disengagement is positively related to drinking frequency, but not drinking quantity. In addition, a significant indirect effect of emotional demands on drinking was observed for drinking frequency only, but not for drinking quantity. So, while exhaustion is a significant predictor of both drinking behaviors, disengagement seems to only be related to how often COs drink rather than how much they are drinking. The conditional influences of recovery experiences were also examined for disengagement and reveal almost mirror opposite effects. While no significant interaction effects were detected for drinking quantity, mastery and disengagement did significantly interact to predict drinking frequency. Mastery does not appear to buffer against the impact of exhaustion, but does appear to be an effective protective mechanism against disengagement. This may be because exhaustion is a state of depleted personal resources 
(Maslach et al., 2001) and without resources it is not likely that mastery experiences will be engaged in as they require an initial investment of regulatory resources. Taken together, these findings suggest that burnout is the mechanism through which emotional demands contribute to drinking, with exhaustion being the primary driver and disengagement contributing more to the frequency with which one drinks. With regard to recovery, those higher in mastery experiences tend to drink less often when disengaged from work than those lower in mastery experiences, whereas those higher in relaxation and detachment experiences tend to drink less when drinking when exhausted than those lower in relaxation and detachment. Thus, recovery experiences may be a fruitful avenue to consider when developing interventions to decrease more problematic forms of $\mathrm{CO}$ drinking as a result of burnout.

In addition to the above findings, this study also contributes to the growing literature on a unique and understudied population, correctional officers. The life expectancy for a CO is about 62 years (Florida State Lodge, 2011). Compared to the national average of about 74 years, it is easy to see that these employees' health and lives have been greatly diminished by their incredibly demanding job. Thus far, there has been an increased focus on work strain within this occupation, but less focus has been allocated to health risk behaviors such as problematic drinking. This is concerning considering that evidence provided by Morse and colleagues (2011) and confirmed by this study shows that a significant percentage of COs are engaging in heavy alcohol use. It is estimated that about five percent of the U.S. population consumes more than 15 
drinks per week, however these authors report that in their sample $11.1 \%$ of COs report drinking to that extent. While the current study did not capture drinking at the week level, $13 \%$ of the COs in our sample report regularly drinking five or more drinks on days when drinking. This level of alcohol use may contribute not only to diminished health for COs, but may also impact social relationships and have serious safety implications due to the nature of the job. It is important to note that because our measure of drinking is an overall measure of alcohol use that we don't know when COs were consuming the drinks recorded. While we assume that at least the majority of these drinks were consumed after work or on days off, it is possible that COs were also drinking before or during work, which may have additional implications for workplace outcomes such as safety (Ames et al., 1997). It is therefore imperative that researchers examine the work and nonwork factors that contribute to and result from CO stress and alcohol use. It is important to point out that not all COs are drinking in concerning quantities or frequencies. While this population is clearly at risk for issues associated with excessive alcohol consumption, our findings did not examine binge drinking. Instead, it revealed associations between burnout, alcohol, and recovery for COs that drink in general. Regardless of the amount consumed, the work environment should not be contributing to alcohol consumption; therefore it is important to outline the practical implications of these findings.

\section{Practical Implications}

First, this study reinforced support for the positive associations between work stressors, strain, and adverse well-being outcomes. In jobs like corrections, emotionally 
demanding situations are inevitable due to the human services nature of the job. Finding that exhaustion is one potential mechanism through which these types of demands contribute to employee drinking provides another avenue through which to intervene and potentially decrease work stress-related drinking. Attempts to reduce employee emotional job demands may decrease the incidence of exhaustion as well as alcohol consumption, and perhaps other poor health behaviors. Considering that the emotionally demanding interactions can not be fully eliminated within this job, teaching COs how to effectively cope with and process these interactions may decrease the risk that they will lead to eventual exhaustion, or at least slow its progression. Within corrections, one coping mechanism in particular, positive comparisons across job types, has been shown to decrease CO work-related stress (Triplett, Mullings, \& Scarborough, 1996). This involves comparing one's current situation to someone else's or to their own at an earlier time and can help bring stressors into perspective. Individuals can use this strategy when they begin to feel emotionally drained at work. A number of suggestions have also been made regarding what organizations can do to decrease $\mathrm{CO}$ stress, including reduction of the inmate-staff ratio and availability of 'time-out' during or after especially taxing situations (Triplett et al., 1996).

This study also found that certain recovery experiences might buffer the impact of burnout on $\mathrm{CO}$ drinking. This knowledge can help with the development of more precise models around work stress-related drinking, as recovery experiences have not yet been examined as moderators in this relationship. In addition, this knowledge can inform 
workplace intervention efforts aimed at decreasing alcohol consumption. If a job does not allow for a reduction in emotional demands due to the nature of the work, as is likely the case in corrections, creating opportunities for employees to recover from their work demands could be useful for reducing $\mathrm{CO}$ drinking. Organizations can create these opportunities by allowing for breaks after demanding or stressful interactions and encouraging officers to use this time to relax or detach from work. Some research indicates that training may help to increase occurrences of recovery experiences. Organizations could also train employees how to engage in some beneficial types of recovery experiences that can help to reduce negative affect and increase recovery-related self-efficacy (Hahn, Binnewies, Sonnentag, \& Mojza, 2011). Additionally, these findings may help identify COs most susceptible to work stress-related drinking, particularly those with high levels of emotional demands and low levels of, or opportunities for, recovery experiences. This information can help organizations target which COs would benefit most from this type of intervention.

The additional analyses also have several practical implications. First, while emotional demands did not directly predict the examined drinking outcomes on their own, emotional demands together with detachment did predict drinking quantity. Specifically, if COs are high in emotional demands and in detachment experiences, they are more likely to consume fewer drinks than if they reported less detachment in their time away from work. This provides an avenue through which we can intervene prior to exhaustion setting in. Encouraging detachment outside of work can protect against 
drinking to cope with or manage emotionally demanding jobs. One way that employers can achieve this is by limiting communication with employees outside of work hours or even during work breaks. While COs may still choose to interact with coworkers during these times, upper management should limit communications with COs and other staff as much as possible. In addition, organizations could also hire more employees to deal with understaffing issues in corrections (Martin, Lichtenstein, Jenkot, \& Forde, 2012) and allow for employees to have enough time away from work in between their work shifts. Within corrections 'bucketing' or mandatory overtime without advance notice is common and limits time available to recover from work. While this may be difficult for organizations to achieve considering that this is a budget issue, attempts to achieve appropriate staffing levels should be prioritized at the very least.

Further, additional analyses indicated that employee exhaustion is not the only mechanism through which emotional demands influence drinking. Together, both exhaustion and disengagement predict drinking outcomes, but in different ways. Additionally, recovery experiences interact differentially with the burnout components to predict drinking. Engaging in more mastery experiences may influence how frequently an officer is drinking, meaning that COs who tend to focus on activities that encourage learning or trying new things that stimulate personal growth, are more likely to drink less frequently than COs who engage in other types of activities. Further, engaging in more relaxing activities, or activities that encourage detaching from work influences the amount of drinking that occurs when COs are drinking. Together, greater levels of these 
three recovery experiences can reduce the impact of burnout on $\mathrm{CO}$ drinking behaviors, therefore it is important that in their time away from work, COs are encouraged to participate in activities that facilitate these types of experiences.

These findings may also have clinical implications that can inform prevention strategies aimed at cutting down on problematic drinking. Considering the finding that certain recovery experiences interact with different aspects of burnout to predict different types of drinking, identifying the antecedents to the particular type of problematic drinking could prove beneficial. For example, for an individual that is drinking too frequently, but is not necessarily drinking concerning amounts, encouraging mastery experiences may be more useful for decreasing drinking than encouraging detachment from work. Since different strategies may be more useful depending on which drinking indicator is more problematic, employees should keep track of how much they are drinking and how frequently they are drinking. Even just this awareness of how much is being consumed could help cut down on more problematic forms of drinking. Additionally, this study may provide insight in to who is most vulnerable to particular forms of problematic drinking. Those that perceive their job as emotionally demanding and do not have more adaptive coping mechanisms in place to deal with these stressors may be more likely to drink.

\section{Limitations and Directions for Future Research}

This study has a number of limitations that should be addressed with future research. First, all measures were self-report which may lead to misreporting, especially 
for health related variables such as alcohol use quantities, which tend to be underreported (Stockwell, Donath, Cooper-Stanbury, Chikritzhs, Catalano, \& Mateo, 2004). Additionally, this research design is subject to common method bias (Podsakoff, MacKenzie, Lee, \& Podsakoff, 2003). Therefore, it is possible that the effect sizes will be somewhat inflated. Regardless, self-report assessments of alcohol have been shown to be a valid and reliable approach to measuring alcohol use, however they can be improved by adding additional measures (Del Boca \& Darkes, 2003) or supplementing self-report assessments with other types of reports such as spouse or supervisor reports.

A second limitation was the cross sectional, between-persons design. Cross sectional designs cannot be used to assess individual change over time or determine causality. Thus, the findings of the study cannot provide conclusive evidence that exhaustion mediates the proposed relationships, as mediation implies a process that occurs over the passage of time. Therefore, explanations of reverse-causation relationships cannot be ruled out. However, past longitudinal research does indicate that stressors lead to strain and that strain predicts adverse well-being outcomes over time (de Jonge \& Dormann, 2006; Garst, Frese, \& Molenaar, 2000; Price, Choi, \& Vinokur, 2002). Future research should test the proposed model using a research design that allows for causal inferences. A within person design may be more appropriate for the specific processes examined, as they likely unfold over the course of the day. Past research indicates that alcohol use varies day-to-day (Armeli, Todd, \& Mohr, 2005; Carney, Armeli, Tennen, Affleck, \& O’Neil, 2000; Liu, Wang, Zhan, \& Shi, 2009; Mohr, Armeli, 
Tennen, Carney, Affleck, \& Hromi, 2001; Mohr, Armeli, Tennen, Todd, Clark, \& Carney, 2005; Wang et al., 2010), thus, the associations between strain, recovery, and alcohol use may be better represented in terms of within person changes utilizing a day level design.

Third, because this sample is such a unique occupational group, the findings may not be generalizable to other occupational groups. However, considering that there are almost half a million people employed as correctional officers within the United States (Bureau of Labor Statistics, 2014), a focus on this group still impacts a large number of individuals. Furthermore, the results may generalize to similar occupational groups such as police officers and active duty military personnel because these occupations utilize a similar hierarchical structure and are inherently dangerous and stressful jobs.

Fourth, health-related outcomes are multi-determined, therefore they are complex to study. We know that any one factor cannot explain the 'lion's share' of variance in health data (Zapf, Dormann, \& Frese, 1996) so we expect to see small effects. However these small effects can still be meaningful when talking about alcohol use, a health outcome with the potential to adversely impact not only employee health and effectiveness, but also organizational effectiveness through detriments on performance and safety. Therefore, determining what types of experiences or conditions can decrease alcohol use are still useful. Future research should examine alcohol use variables that are more specific including temporal and social context of use to better understand how the 
work environment differentially influences different types of drinking. Different drinking contexts may be associated with different health related outcomes.

Finally, future research should also examine how the process of recovery from work and drinking overlap. While recovery experiences may be an effective buffer between strain and more problematic forms of drinking, it is possible that light to moderate alcohol use facilitates recovery from work, where activities engaged in to recover from work also include the consumption of alcohol. In addition, recovery experiences may facilitate alcohol use, where doing something relaxing stimulates the desire to have a drink. Thus, a more thorough investigation of the interrelationships between recovery from work and alcohol use needs to be undertaken at the day level.

\section{Conclusion}

In conclusion, this study identified both exhaustion and disengagement as mechanisms that can help to explain why COs may drink alcohol to cope with workrelated demands. In addition, this study was the first to examine how recovery from work and alcohol use are associated. Certain recovery experiences may act as buffers between burnout and diminish drinking to cope with that strain, and different experiences impact different types of drinking. Thus, this study has identified several paths through which emotional job demands within the corrections environment contribute to CO drinking, as well as a potential way to mitigate the influence of these demands on drinking. Due to the consequences associated with working as a correctional officer, it is imperative that we 
test these associations among this unique occupational group in an attempt to identify protective factors that may help to prolong their health and their lives. 


\section{Tables}

Table 1

Survey Measures

Emotional Workload (Van Veldhoven and Meijman, 1994)

1. Did your work demand a lot from you emotionally?

2. Were you confronted with things that affected you emotionally in your work?

3. Did your work put you in emotionally upsetting situations?

Response Options: (1) Very rarely or never to (5) Several times an hour.

\section{Days of Alcohol Consumption}

In the past month...

On how many days did you consume alcohol?

\section{Average Drinks per day}

In the past month...

When you did drink, on average, how many drinks did you have in a day? (One drink can be one $12 \mathrm{oz}$. beer or wine cooler, one $5 \mathrm{oz}$. glass of wine, or $1.5 \mathrm{oz}$. liquor)

Exhaustion (Demerouti et al., 2003)

To what extent do you agree with the following statements? In the past month...

1. There were days that I felt already tired before I went to work.

2. After my work, I needed more time to relax than in the past to become fit again.

3. I could stand the pressure of my work very well. *

4. During my work, I often felt emotionally drained.

5. After my work, I usually felt still totally fit for my leisure activities. *

6. After my work, I usually felt worn out and weary.

7. When I worked, I usually felt vital. *

8. I could manage the amount of work well. *

Response Options: (1) Not at all to (5) Very much.

*Indicates reverse-coded items

Recovery Experience Questionnaire (Sonnentag \& Fritz, 2007)

To what extent do you agree with the following statements? OUTSIDE OF

WORK, in the past month...

Mastery

1. I learned new things.

2. I sought out mental challenges. 
3. I did things that challenged me.

4. I did something to broaden my horizons.

Control

1. I felt like I could decide for myself what to do.

2. I determined for myself how I spent my time.

3. I took care of things the way that I wanted them done.

4. I decided my own schedule.

Detachment

1. I forgot about work.

2. I didn't think about work at all.

3. I distanced myself from work.

4. I got a break from the demands of work.

Relaxation

1. I kicked back and relaxed.

2. I did things that were relaxing.

3. I used the time to relax.

4. I took time for leisure.

Response Options: (1) Not at all to (5) Very much.

Negative Affect (Watson \& Clark, 1999)

To what extent do you experience the following moods in general?

1. Scared

2. Afraid

3. Upset

4. Distressed

5. Jittery

6. Nervous

7. Ashamed

8. Guilty

9. Irritable

10. Hostile

Response Options: (1) Never to (5) Always.

\section{Gender}

What is your gender?

Response Options: (Circle one): (a) Male or (b) Female.

Age

What is your age?

Fill-in: years

Which shift do you currently work?

Which best describes the shift you work? 


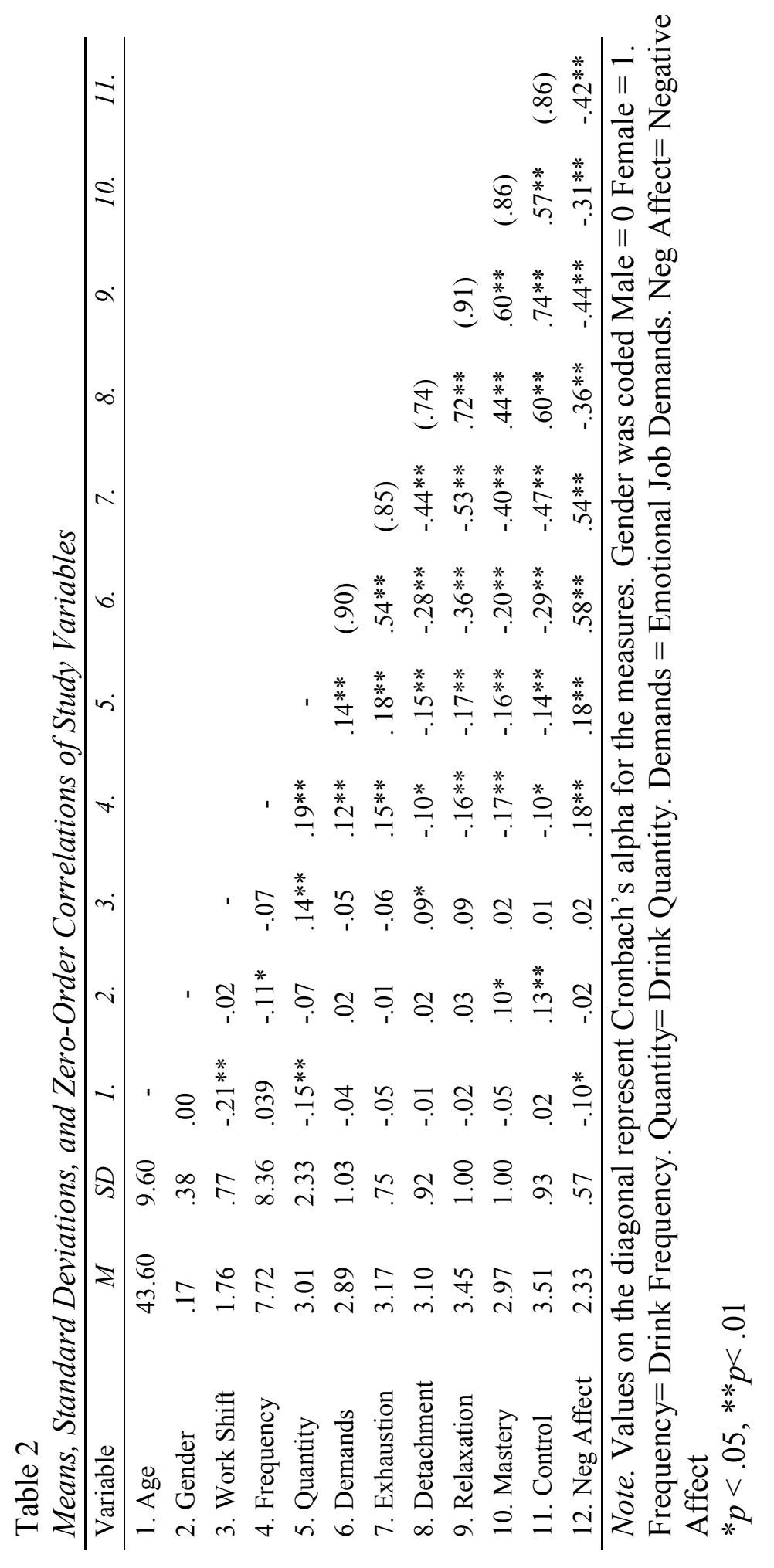


Table 3

Hypothesized Direct and Interaction Effects on CO Drinking and Exhaustion

\begin{tabular}{lrrrrrr}
\hline & \multicolumn{2}{c}{ Drinking Quantity } & \multicolumn{2}{c}{ Drinking Frequency } & \multicolumn{2}{c}{ Exhaustion } \\
\cline { 2 - 7 } & $\beta(\mathrm{SE})$ & $\mathrm{p}$ & $\beta(\mathrm{SE})$ & $\mathrm{p}$ & $\beta(\mathrm{SE})$ & $\mathrm{p}$ \\
\hline Emotional Load*NA & $-.09(.16)$ & .58 & $-.78(.62)$ & .21 & & \\
Emotional Load & & & & & $.40(.03)$ & $<.001$ \\
Exhaustion & $.35(.16)$ & .03 & $1.30(60)$ & .03 & & \\
Exhaustion*Mastery & $-.08(.11)$ & .45 & $-.67(.45)$ & .14 & & \\
Exhaustion*Relaxation & $-.24(.11)$ & .04 & $-.69(.54)$ & .20 & & \\
Exhaustion*Detach & $-.26(.12)$ & .03 & $-.33(.63)$ & .60 & & \\
Exhaustion*Control & $-.17(.14)$ & .20 & $-.58(.60)$ & .34 & & \\
\hline
\end{tabular}

Note. Detach $=$ Detachment

Table 4

Indirect Effects of Emotional Demands on CO Drinking Through Exhaustion

\begin{tabular}{lrrrr}
\hline & Est. & SE & BootLLCI & BootULCI \\
\hline Drinking Quantity & .14 & .06 & .021 & .271 \\
Drinking Frequency & .52 & .24 & .070 & 1.00 \\
\hline
\end{tabular}

Table 5

Regression Results for a Moderated Mediation Model of Emotional Demands on Drinking Through Exhaustion with Recovery Experiences as Moderators of the Relationship Between Exhaustion and Drinking Outcomes

\begin{tabular}{lrrrrrrrr}
\hline & \multicolumn{3}{c}{ Drinking Quantity } & \multicolumn{3}{c}{ Drinking Frequency } \\
\cline { 2 - 9 } Moderator & Index & SE(Boot) & LLCI & ULCI & Index & SE(Boot) & LLCI & ULCI \\
\hline Mastery & -.02 & .04 & -.118 & .062 & -.24 & .18 & -.620 & .087 \\
Relaxation & -.09 & .05 & -.190 & -.004 & -.27 & .21 & -.693 & .125 \\
Detach & -.10 & .05 & -.197 & -.003 & -.10 & .25 & -.601 & .383 \\
Control & -.07 & .06 & -.181 & .035 & -.22 & .23 & -.733 & .197 \\
\hline
\end{tabular}

Note. Detach= Detachment.

Table 6

Direct and Interaction Effects on CO Drinking and Disengagement

\begin{tabular}{llcrrrr}
\hline \multirow{2}{*}{ Predictor } & \multicolumn{2}{c}{ Disengagement } & \multicolumn{2}{c}{ Drinking Quantity } & \multicolumn{2}{c}{ Drinking Frequency } \\
\cline { 2 - 7 } & $\beta(\mathrm{SE})$ & $\mathrm{p}$ & $\beta(\mathrm{SE})$ & $\mathrm{p}$ & $\beta(\mathrm{SE})$ & \multicolumn{1}{c}{$\mathrm{p}$} \\
\hline Emotional Load & $.18(.03)$ & $<.001$ & & & & \\
Disengagement & & & $.21(.15)$ & .17 & $2.22(.56)$ & $<.001$ \\
Disengagement*Mastery & & & $-.05(.14)$ & .71 & $-1.12(.50)$ & .03 \\
Disengagement*Relax & & & $-.10(.11)$ & .40 & $-.63(.54)$ & .25 \\
Disengagement*Detach & & & $.05(.15)$ & .72 & $.14(.62)$ & .82 \\
Disengagement*Control & & & $-.17(.13)$ & .18 & $-1.06(.58)$ & .07 \\
\hline
\end{tabular}

Note. Relax $=$ Relaxation. Detach $=$ Detachment 
Table 7

Indirect Effects of Emotional Demands on CO Drinking Through Disengagement

\begin{tabular}{lrrrr}
\hline & Est. & SE & BootLLCI & BootULCI \\
\hline Drinking Quantity & .04 & .03 & -.015 & .096 \\
Drinking Frequency & .41 & .13 & .179 & .730 \\
\hline
\end{tabular}

Table 8

Summary of Study Findings

\begin{tabular}{|c|c|c|}
\hline & Relationship & Supported? \\
\hline H1 & Emotional Load*NA $\rightarrow$ Drink Quantity and Frequency & No \\
\hline $\mathrm{H} 2$ & Emotional Load $\rightarrow$ Exhaustion & Yes \\
\hline $\mathrm{H} 3$ & Exhaustion $\rightarrow$ Drink Quantity and Frequency & Yes \\
\hline $\mathrm{H} 4$ & Emotional Load $\rightarrow$ Exhaustion $\rightarrow$ Drink Quantity and Frequency & Yes \\
\hline H5a & Exhaustion*Mastery $\rightarrow$ Drink Quantity and Frequency & $\mathrm{N} \square$ \\
\hline $\mathrm{H} 5 \mathrm{~b}$ & Exhaustion*Relax $\rightarrow$ Drink Quantity and Frequency & Partial (Quantity only) \\
\hline $\mathrm{H} 5 \mathrm{c}$ & Exhaustion*Detach $\rightarrow$ Drink Quantity and Frequency & Partial (Quantity only) \\
\hline RQ1a & $\begin{array}{l}\text { Second Stage ModMed: Exhaustion as Mediator, Mastery as } \\
\text { Moderator }\end{array}$ & No \\
\hline RQ1b & $\begin{array}{l}\text { Second Stage ModMed: Exhaustion as Mediator, Relaxation as } \\
\text { Moderator }\end{array}$ & Partial (Quantity only) \\
\hline RQ1c & $\begin{array}{l}\text { Second Stage ModMed: Exhaustion as Mediator, Detachment as } \\
\text { Moderator }\end{array}$ & Partial (Quantity only) \\
\hline RQ2 & Exhaustion*Control $\rightarrow$ Drink Quantity and Frequency & No \\
\hline RQ3 & Drinking Quantity and Frequency $\rightarrow$ Detach and Relax & Yes \\
\hline AA1a & Emotional Load*Mastery $\rightarrow$ Drink Quantity and Frequency & No \\
\hline AA1b & Emotional Load*Relaxation $\rightarrow$ Drink Quantity and Frequency & No \\
\hline AA1c & Emotional Load*Detachment $\rightarrow$ Drink Quantity and Frequency & Partial (Quantity only) \\
\hline AA2a-c & Emotional Load*Recovery Experiences $\rightarrow$ Exhaustion & No \\
\hline AA3a-c & $\begin{array}{l}\text { First Stage ModMed: Exhaustion as Med, Recovery Experiences } \\
\text { as Moderators }\end{array}$ & No \\
\hline AA4 & Emotional Load $\rightarrow$ Disengagement & Yes \\
\hline AA5 & Disengagement $\rightarrow$ Drink Quantity and Frequency & $\begin{array}{l}\text { Partial (Frequency } \\
\text { only) }\end{array}$ \\
\hline AA6 & $\begin{array}{l}\text { Emotional Load } \rightarrow \text { Disengagement } \rightarrow \text { Drink Quantity and } \\
\text { Frequency }\end{array}$ & $\begin{array}{l}\text { Partial (Frequency } \\
\text { only) }\end{array}$ \\
\hline AA7a & Disengagement*Mastery $\rightarrow$ Drink Quantity and Frequency & $\begin{array}{l}\text { Partial (Frequency } \\
\text { only) }\end{array}$ \\
\hline AA7b & Disengagement*Relax $\rightarrow$ Drink Quantity and Frequency & No \\
\hline AA7c & Disengagement*Detach $\rightarrow$ Drink Quantity and Frequency & No \\
\hline AA7d & Disengagement*Control $\rightarrow$ Drink Quantity and Frequency & No \\
\hline AA8a & $\begin{array}{l}\text { Second Stage ModMed: Disengagement as Mediator, Mastery as } \\
\text { Moderator }\end{array}$ & $\begin{array}{l}\text { Partial (Frequency } \\
\text { only) }\end{array}$ \\
\hline AA $8 b$ & $\begin{array}{l}\text { Second Stage ModMed: Disengagement as Mediator, Relaxation } \\
\text { as Moderator }\end{array}$ & No \\
\hline AA8c & $\begin{array}{l}\text { Second Stage ModMed: Disengagement as Mediator, Detachment } \\
\text { as Moderator }\end{array}$ & No \\
\hline
\end{tabular}

Note: $\mathrm{H}=$ hypothesis, $\mathrm{RQ}=$ research question, and $\mathrm{AA}=$ additional analysis. 


\section{Figures}

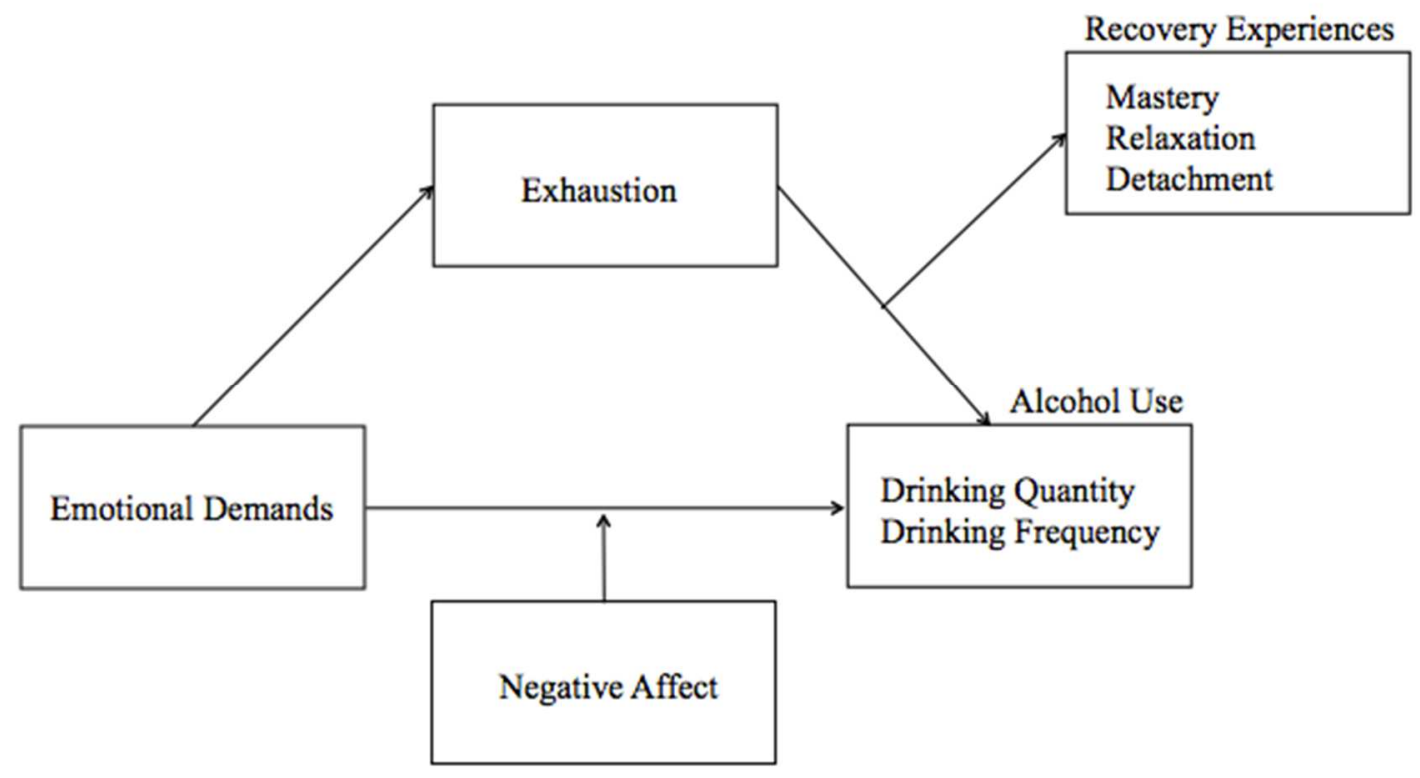

Figure 1. Hypothesized Conceptual Model 


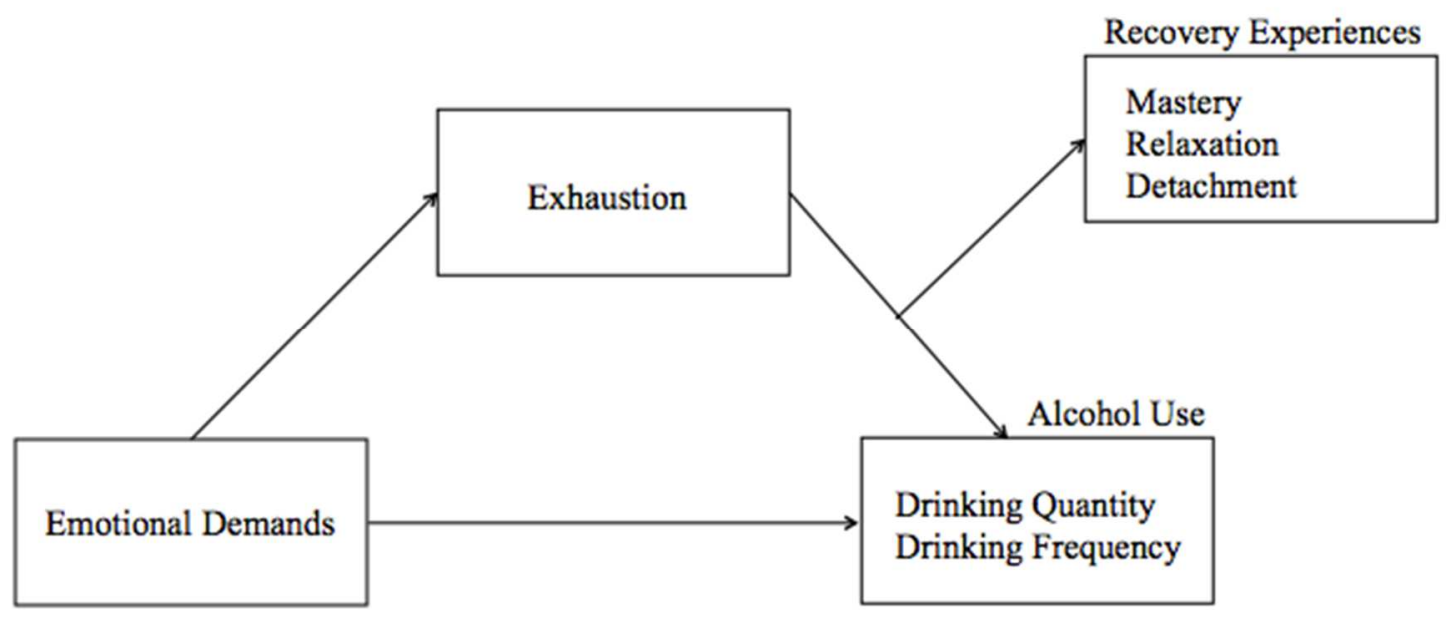

Figure 2. Research Question 1 Conceptual Model: Second Stage Moderated Mediation 


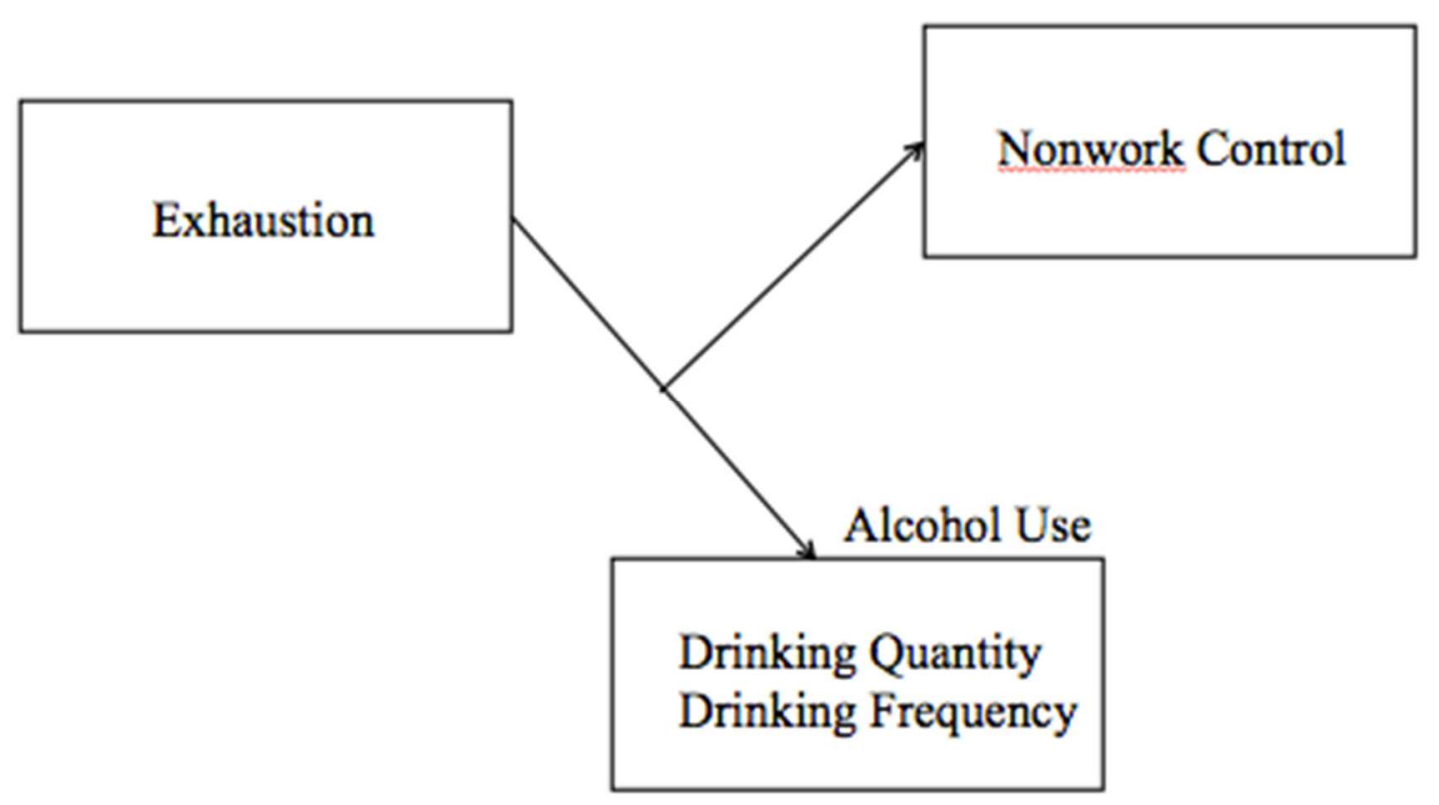

Figure 3. Research Question 2 Conceptual Model: Nonwork Control as a Moderator 


\begin{tabular}{|c|c|}
\hline Alcohol Use & Recovery Experiences \\
\hline \multirow{2}{*}{$\begin{array}{l}\text { Drinking Quantity } \\
\text { Drinking Frequency }\end{array}$} & Relaxation \\
\hline & Detachment \\
\hline
\end{tabular}

Figure 4. Research Question 3 Conceptual Model: Drinking Behaviors Predicting Recovery Experiences 


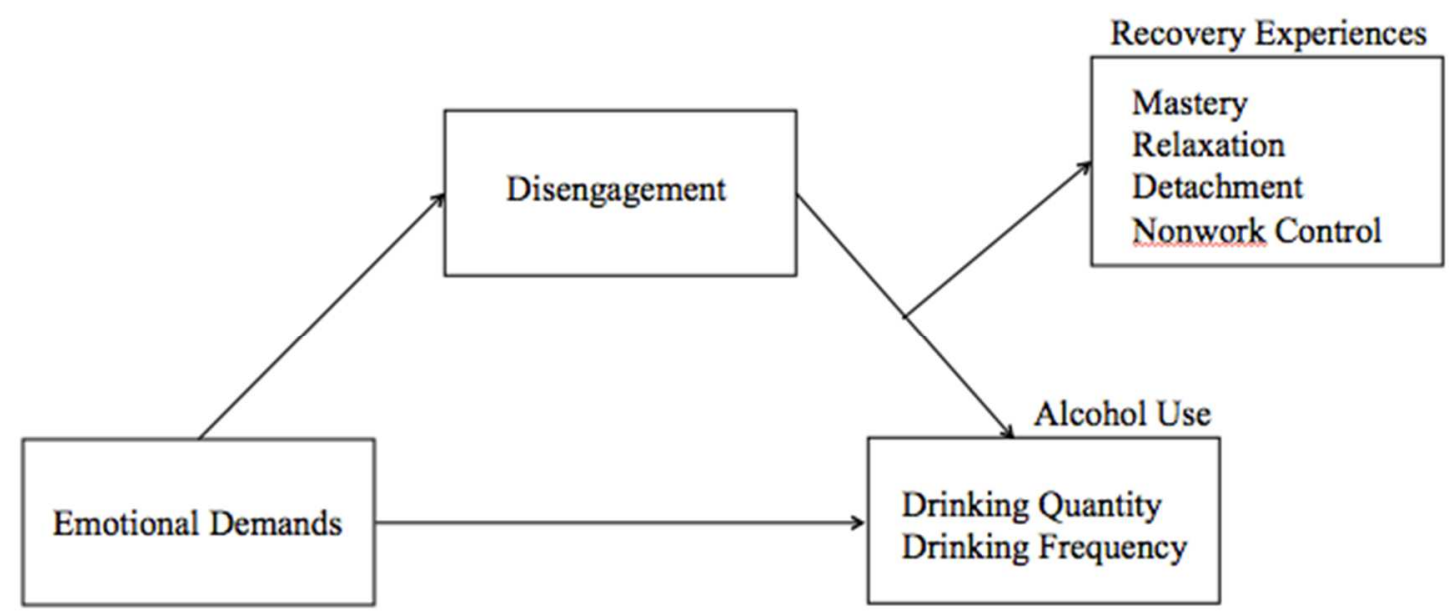

Figure 5. Additional Analyses Conceptual Model: Disengagement as a Mediator 


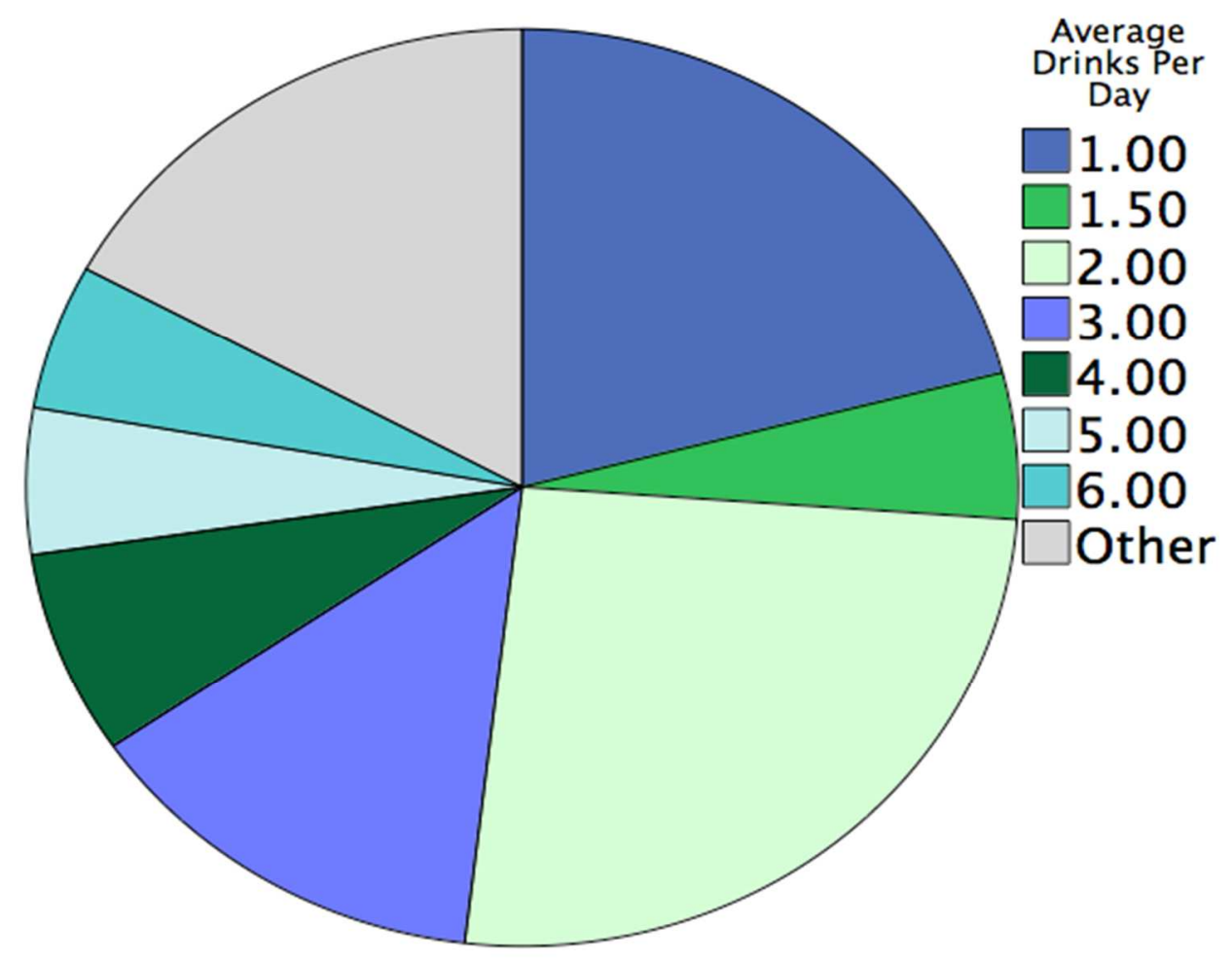

Figure 6. Pie chart for average drinks per day on days when drinking. Note: 'other' refers to 7 or more drinks per day on average 


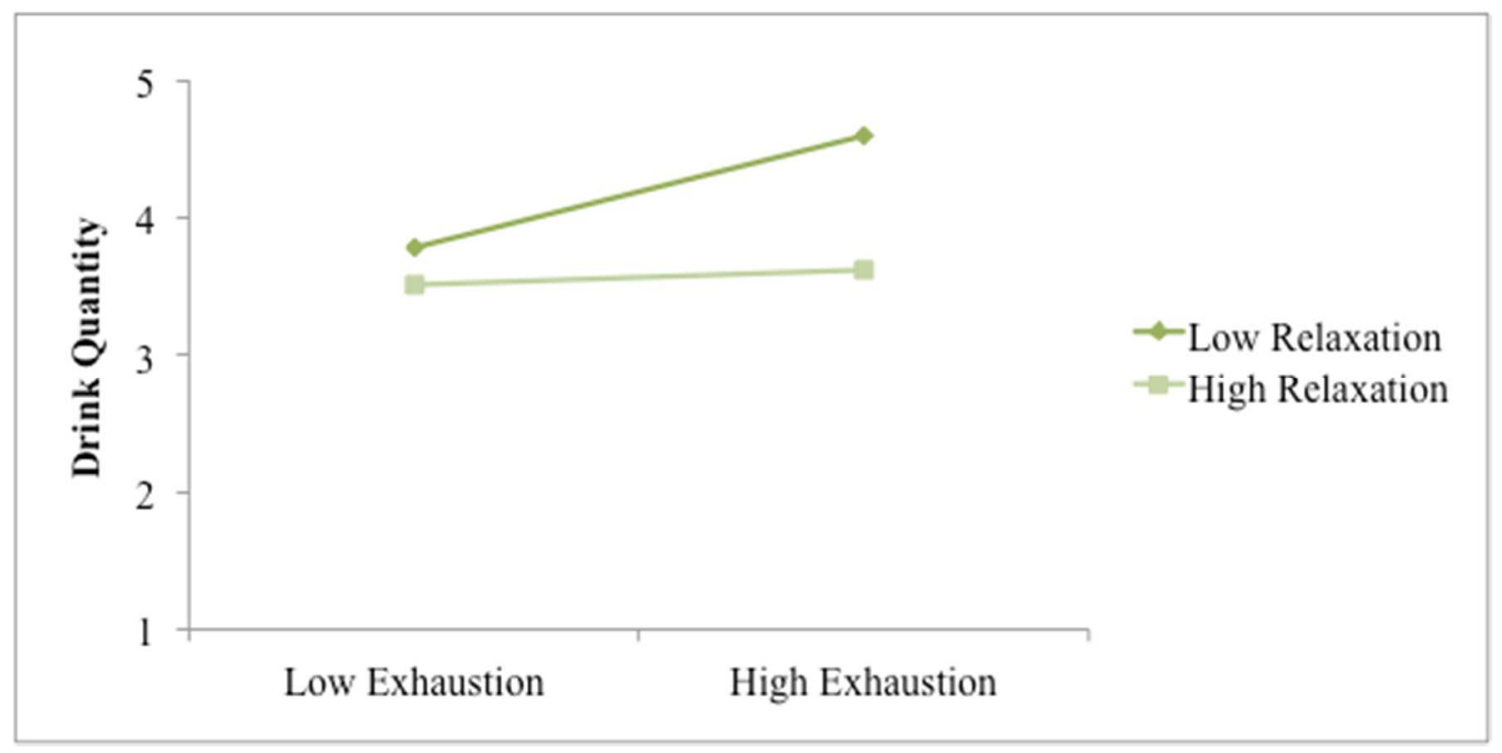

Figure 7. Graph of the Interaction Effects of Relaxation and Exhaustion on Drink Quantity

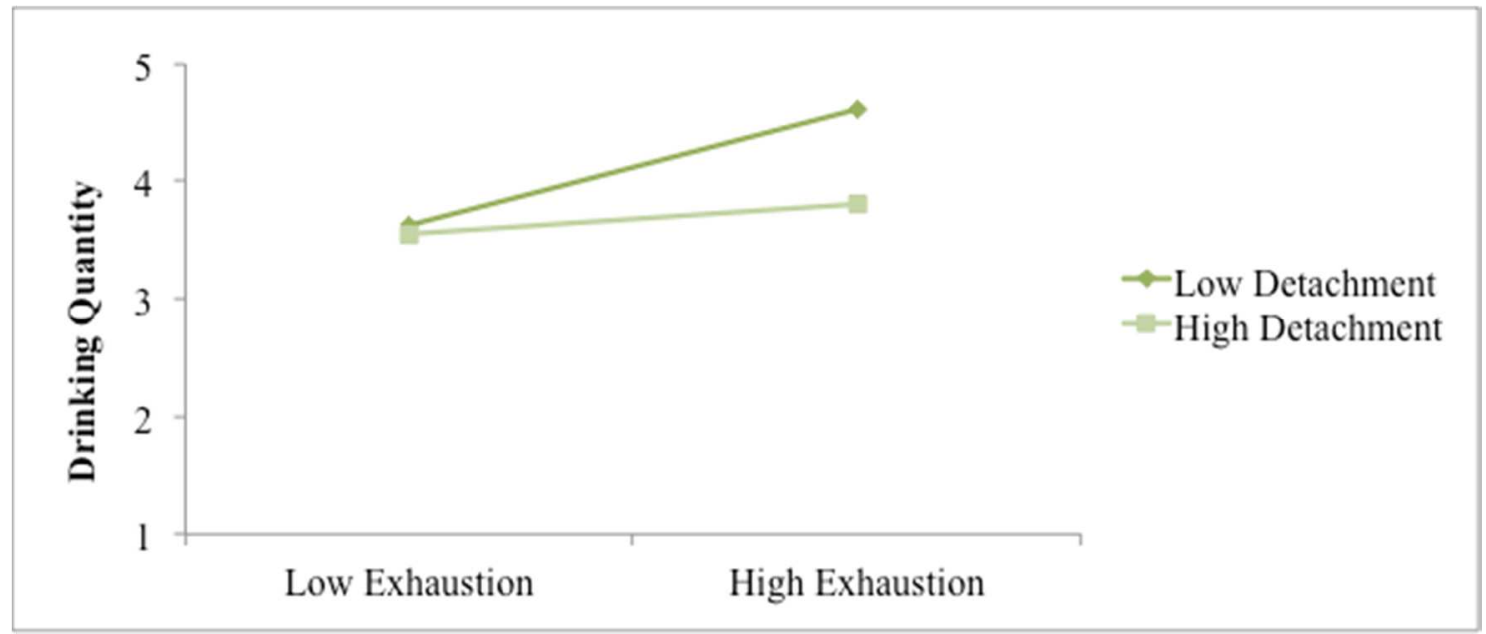

Figure 8. Graph of the Interaction Effects of Detachment and Exhaustion on Drink Quantity 


\author{
References \\ Adams, R. E., Boscarino, J. A., \& Galea, S. (2006). Social and psychological resources \\ and health outcomes after the World Trade Center disaster. Social Science \\ \& Medicine, 62, 176-188.
}

Ames, G. M., Grube, J. W., \& Moore, R. S. (1997). The relationship of drinking and hangovers to workplace problems: An empirical study. Journal of Studies on Alcohol, 58, 37-47.

Armeli, S., Carney, M. A., Tennen, H., Affleck, G., \& O'Neil, T. (2000). Stress and alcohol use: A daily process examination of the stressor-vulnerability model. Journal of Personality and Social Psychology, 78, 979-994.

Armeli, S., DeHart, T., Tennen, H., Todd, M., \& Affleck, G. (2007). Daily interpersonal stress and the stressor-vulnerability model of alcohol use. Journal of Social and Clinical Psychology, 26, 896-921.

Armeli, S., Tennen, H., Affleck, G., \& Kranzler, H. R. (2000). Does affect mediate the association between daily events and alcohol use?. Journal of Studies on Alcohol, 61, 862-871.

Armeli, S., Todd, M., \& Mohr, C. (2005). A daily process approach to individual differences in stress-related alcohol use. Journal of Personality, 73, 1657-1686

Bacharach, S. B., Bamberger, P. A., \& Sonnenstuhl, W. J. (2002). Driven to drink: Managerial control, work-related risk factors, and employee problem drinking. Academy of Management Journal, 45, 637-658. 
Bakker, A. B., \& Demerouti, E. (2007). The job demands-resources model: State of the art. Journal of Managerial Psychology, 22, 309-328.

Bakker, A. B., Demerouti, E., \& Euwema, M. C. (2005). Job resources buffer the impact of job demands on burnout. Journal of Occupational Health Psychology, 10, 170180.

Bakker, A., Demerouti, E., \& Schaufeli, W. (2003). Dual processes at work in a call centre: An application of the job demands-resources model. European Journal of Work and Organizational Psychology, 12, 393-417.

Bakker, A. B., Demerouti, E., \& Verbeke, W. (2004). Using the job demands-resources model to predict burnout and performance. Human Resource Management, 43, $83-104$.

Baron, R. M., \& Kenny, D. A. (1986). The moderator-mediator variable distinction in social psychological research: Conceptual, strategic, and statistical considerations. Journal of Personality and Social Psychology, 51, 1173-1182.

Baumeister, R. F., Bratslavsky, E., Muraven, M., \& Tice, D. M. (1998). Ego depletion: Is the active self a limited resource?. Journal of Personality and Social Psychology, $74,1252-1265$.

Becker, T. E. (2005). Potential problems in the statistical control of variables in organizational research: A qualitative analysis with recommendations. Organizational Research Methods, 8, 274-289. 
Bernerth, J. B., \& Aguinis, H. (2015). A critical review and best-practice recommendations for control variable usage. Personnel Psychology, 00, 1-55

Biron, M., Bamberger, P. A., \& Noyman, T. (2011). Work-related risk factors and employee substance use: Insights from a sample of Israeli blue-collar workers. Journal of Occupational Health Psychology, 16, 247-263.

Bliese, P. D., \& Jex, S. M. (2002). Incorporating a mulitilevel perspective into occupational stress research: Theoretical, methodological, and practical implications. Journal of Occupational Health Psychology, 7, 265-276.

Blum, T. C., Roman, P. M., \& Martin, J. K. (1993). Alcohol consumption and work performance. Journal of Studies on Alcohol, 54, 61-70.

Bouchery, E. E., Harwood, H. J., Sacks, J. J., Simon, C. J., \& Brewer, R. D. (2011). Economic costs of excessive alcohol consumption in the US, 2006. American Journal of Preventive Medicine, 41, 516-524.

Bureau of Labor Statistics (2015). U.S. Department of Labor, Occupational Outlook Handbook, 2014-15 Edition, Correctional Officers. Retrieved from: http://www.bls.gov/ooh/protective-service/correctional-officers.htm

Butler, A. B., Dodge, K. D., \& Faurote, E. J. (2010). College student employment and drinking: A daily study of work stressors, alcohol expectancies, and alcohol consumption. Journal of Occupational Health Psychology, 15, 291-303. 
Carney, M. A., Armeli, S., Tennen, H., Affleck, G., \& O'Neil, T. P. (2000). Positive and negative daily events, perceived stress, and alcohol use: A diary study. Journal of Consulting and Clinical Psychology, 68, 788-798.

Centers for Disease Control and Prevention. (2014). Excessive drinking costs U.S. \$223.5 billion. Retrieved from: http://www.cdc.gov/features/alcoholconsumption/

Chen, M. J., \& Cunradi, C. (2008). Job stress, burnout and substance use among urban transit operators: The potential mediating role of coping behaviour. Work \& Stress, 22, 327-340.

Conger, J. J. (1956). Reinforcement theory and the dynamics of alcoholism. Quarterly Journal of Studies on Alcohol, 17, 296-305

Cooper, M. L. (1994). Motivations for alcohol use among adolescents: Development and validation of a four-factor model. Psychological Assessment, 6, 117-128.

Cooper, M. L., Frone, M. R., Russell, M., \& Mudar, P. (1995). Drinking to regulate positive and negative emotions: A motivational model of alcohol use. Journal of Personality and Social Psychology, 69, 990-1005.

Cooper, M. L., Russell, M., \& Frone, M. R. (1990). Work stress and alcohol effects: A test of stress-induced drinking. Journal of Health and Social Behavior, 31, 260276.

Cooper, M. L., Russell, M., Skinner, J. B., Frone, M. R., \& Mudar, P. (1992). Stress and alcohol use: Moderating effects of gender, coping, and alcohol expectancies. Journal of Abnormal Psychology, 101, 139-152. 
Coxe, S., West, S. G., \& Aiken, L. S. (2009). The analysis of count data: A gentle introduction to Poisson regression and its alternatives. Journal of Personality Assessment, 91, 121-136.

Cunradi, C. B., Greiner, B. A., Ragland, D. R., \& Fisher, J. (2005). Alcohol, stressrelated factors, and short-term absenteeism among urban transit operators. Journal of Urban Health, 82, 43-57.

Darr, W., \& Johns, G. (2008). Work strain, health, and absenteeism: A meta-analysis. Journal of Occupational Health Psychology, 13, 293-318.

De Jonge, J., \& Dormann, C. (2006). Stressors, resources, and strain at work: A longitudinal test of the triple-match principle. Journal of Applied Psychology, 91, $1359-1374$.

Deci, E. L., \& Ryan, R. M. (1987). The support of autonomy and the control of behavior. Journal of Personality and Social Psychology, 53, 1024-1037.

Del Boca, F. K., \& Darkes, J. (2003). The validity of self-reports of alcohol consumption: State of the science and challenges for research. Addiction, 98, 1-12.

Demerouti, E., Bakker, A. B., \& Schaufeli, W. B. (2005). Spillover and crossover of exhaustion and life satisfaction among dual-earner parents. Journal of Vocational Behavior, 67, 266-289.

Demerouti, E., Bakker, A. B., Nachreiner, F., \& Schaufeli, W. B. (2001). The job demands-resources model of burnout. Journal of Applied Psychology, 86, 499512. 
Demerouti, E., Bakker, A. B., Vardakou, I., \& Kantas, A. (2003). The convergent validity of two burnout instruments: A multitrait-multimethod analysis. European Journal of Psychological Assessment, 19, 12.

Diener, E., \& Emmons, R. A. (1984). The independence of positive and negative affect. Journal of Personality and Social Psychology, 47, 1105-1117.

Duncan, G. J., Wilkerson, B., \& England, P. (2006). Cleaning up their act: The effects of marriage and cohabitation on licit and illicit drug use. Demography, 43, 691-710.

Fillmore, M. T., \& Vogel-Sprott, M. (2000). Response inhibition under alcohol: Effects of cognitive and motivational conflict. Journal of Studies on Alcohol, 61, 239246.

Florida State Lodge (2011). Florida mortality study: Florida law enforcement and corrections officers compared to Florida general population, Retrieved from http://nicic.gov/library/025430

Fritz, C., \& Sonnentag, S. (2006). Recovery, well-being, and performance-related outcomes: The role of workload and vacation experiences. Journal of Applied Psychology, 91, 936-945.

Fritz, C., Sonnentag, S., Spector, P. E., \& McInroe, J. A. (2010). The weekend matters: Relationships between stress recovery and affective experiences. Journal of Organizational Behavior, 31, 1137-1162.

Frone, M. R. (1999). Work stress and alcohol use. Alcohol Research and Health, 23, 284291. 
Frone, M. R. (2003). Predictors of overall and on-the-job substance use among young workers. Journal of Occupational Health Psychology, 8, 39-54.

Frone, M. R. (2008). Are work stressors related to employee substance use? The importance of temporal context assessments of alcohol and illicit drug use. Journal of Applied Psychology, 93, 199-206.

Frone, M. R. (2013). Alcohol and illicit drug use in the workforce and workplace. Washington, DC: American Psychological Association. http://dx.doi.org/10.1037/13944-000

Frone, M. R. (2015). Relations of negative and positive work experiences to employee alcohol use: Testing the intervening role of negative and positive work rumination. Journal of Occupational Health Psychology, 20, 148-160.

Frone, M. R., Barnes, G. M., \& Farrell, M. P. (1994). Relationship of work-family conflict to substance use among employed mothers: The role of negative affect. Journal of Marriage and the Family, 56, 1019-1030.

Frone, M. R., Russell, M., \& Cooper, M. L. (1993). Relationship of work-family conflict, gender, and alcohol expectancies to alcohol use/abuse. Journal of Organizational Behavior, 14, 545-558.

Frone, M. R., Russell, M., \& Cooper, M. L. (1997). Relation of work-family conflict to health outcomes: A four-year longitudinal study of employed parents. Journal of Occupational and Organizational Psychology, 70, 325-335. 
Garst, H., Frese, M., \& Molenaar, P. (2000). The temporal factor of change in stressorstrain relationships: A growth curve model on a longitudinal study in East Germany. Journal of Applied Psychology, 85, 417-438.

Geurts, S. A., \& Sonnentag, S. (2006). Recovery as an explanatory mechanism in the relation between acute stress reactions and chronic health impairment. Scandinavian Journal of Work, Environment \& Health, 32, 482-492.

Grunberg, L., Moore, S., \& Greenberg, E. S. (1998). Work stress and problem alcohol behavior: A test of the spillover model. Journal of Organizational Behavior, 19, 487-502.

Grunberg, L., Moore, S., Anderson-Connolly, R., \& Greenberg, E. (1999). Work stress and self-reported alcohol use: The moderating role of escapist reasons for drinking. Journal of Occupational Health Psychology, 4, 29-36.

Hahn, V. C., Binnewies, C., Sonnentag, S., \& Mojza, E. J. (2011). Learning how to recover from job stress: Effects of a recovery training program on recovery, recovery-related self-efficacy, and well-being. Journal of Occupational Health Psychology, 16, 202-216.

Harrington, J. M. (2001). Health effects of shift work and extended hours of work. Occupational and Environmental Medicine, 58, 68-72.

Hobfoll, S. E. (1989). Conservation of resources: A new attempt at conceptualizing stress. American Psychologist, 44, 513-524. 
Hofmann, W., Rauch, W., \& Gawronski, B. (2007). And deplete us not into temptation: Automatic attitudes, dietary restraint, and self-regulatory resources as determinants of eating behavior. Journal of Experimental Social Psychology, 43, 497-504.

Holloway, E A. (1994). Low-dose alcohol effects on human performance: A review of post-1984 research (Office of Aviation Medicine Report No. DOT/FAA/AM94/24). Washington, DC: Federal Aviation Administration.

Holmila, M., \& Raitasalo, K. (2005). Gender differences in drinking: Why do they still exist?. Addiction, 100, 1763-1769. doi: 10.1111/j.1360-0443.2005.01249.x

Johnson, P. B., \& Gurin, G. (1994). Negative affect, alcohol expectancies and alcoholrelated problems. Addiction, 89, 581-586.

Kouvonen, A., Kivimäki, M., Cox, S. J., Poikolainen, K., Cox, T., \& Vahtera, J. (2005). Job strain, effort-reward imbalance, and heavy drinking: A study in 40,851 employees. Journal of Occupational and Environmental Medicine, 47, 503-513.

Larson, R. (1989). Is feeling" in control" related to happiness in daily life?. Psychological Reports, 64, 775-784.

Le Blanc, P. M., Bakker, A. B., Peeters, M. C., van Heesch, N. C., \& Schaufeli, W. B. (2001). Emotional job demands and burnout among oncology care providers. Anxiety, Stress and Coping, 14, 243-263.

Lehman, W. E., \& Simpson, D. D. (1992). Employee substance use and on-the-job behaviors. Journal of Applied Psychology, 77, 309-321. 
Liu, S., Wang, M., Zhan, Y., \& Shi, J. (2009). Daily work stress and alcohol use: Testing the cross-level moderation effects of neuroticism and job involvement. Personnel Psychology, 62, 575-597.

Maisto, S. A., Carey, K. B., \& Bradizza, C. M. (1999). Social learning theory. Psychological theories of drinking and alcoholism, 106.

Mangione, T. W., Howland, J., Amick, B., Cote, J., Lee, M., Bell, N., \& Levine, S. (1999). Employee drinking practices and work performance. Journal of Studies on Alcohol, 60, 261-270.

Martin, J. L., Lichtenstein, B., Jenkot, R. B., \& Forde, D. R. (2012). They can take us over any time they want: Correctional officers' responses to prison crowding. The Prison Journal, 92, 88-105.

Maslach, C. (1978). Job burnout: How people cope. Public Welfare, 36, 56-58.

Maslach, C., Schaufeli, W. B., \& Leiter, M. P. (2001). Job burnout. Annual Review of Psychology, 52, 397-422.

McFarlin, S. K., \& Fals-Stewart, W. (2002). Workplace absenteeism and alcohol use: A sequential analysis. Psychology of Addictive Behaviors, 16, 17-21.

Meijman, T. F., \& Mulder, G. (1998). Psychological aspects of workload. Handbook of Work and Organizational Psychology. 2.

Mirvis, P. H., \& Lawler, E. E. (1977). Measuring the financial impact of employee attitudes. Journal of Applied Psychology, 62, 1-8. 
Mohr, C. D., Armeli, S., Tennen, H., Carney, M. A., Affleck, G., \& Hromi, A. (2001). Daily interpersonal experiences, context, and alcohol consumption: Crying in your beer and toasting good times. Journal of Personality and Social Psychology, $80,489-500$.

Mohr, C. D., Armeli, S., Tennen, H., Temple, M., Todd, M., Clark, J., \& Carney, M. A. (2005). Moving beyond the keg party: A daily process study of college student drinking motivations. Psychology of Addictive Behaviors, 19, 392-403.

Muraven, M., \& Baumeister, R. F. (2000). Self-regulation and depletion of limited resources: Does self-control resemble a muscle?. Psychological Bulletin, 126, 247-259.

Muraven, M., Collins, R. L., \& Neinhaus, K. (2002). Self-control and alcohol restraint: An initial application of the self-control strength model. Psychology of Addictive Behaviors, 16, 113-120.

Naisberg-Fennig, S., Fennig, S., Keinan, G., \& Elizur, A. (1991). Personality characteristics and proneness to burnout: A study among psychiatrists. Stress Medicine, 7, 201-205.

National Institute on Alcohol Abuse and Alcoholism (2004). NIAAA Council Approves Definition of Binge Drinking. NIAAA Newsletter. Retrieved from:

http://pubs.niaaa.nih.gov/publications/Newsletter/winter2004/Newsletter_Number3.pdf

Ng, D. M., \& Jeffery, R. W. (2003). Relationships between perceived stress and health behaviors in a sample of working adults. Health Psychology, 22, 638-642. 
Philliber, S. (1987). Thy brother's keeper: A review of the literature on correctional officers. Justice Quarterly, 4, 9-37.

Podsakoff, P. M., MacKenzie, S. B., Lee, J. Y., \& Podsakoff, N. P. (2003). Common method biases in behavioral research: A critical review of the literature and recommended remedies. Journal of Applied Psychology, 88, 879-903.

Pohorecky, L. A. (1991). Stress and alcohol interaction: An update of human research. Alcoholism: Clinical and Experimental Research, 15, 438-459.

Preacher, K. J., Rucker, D. D., \& Hayes, A. F. (2007). Addressing moderated mediation hypotheses: Theory, methods, and prescriptions. Multivariate Behavioral Research, 42, 185-227.

Price, R. H., Choi, J. N., \& Vinokur, A. D. (2002). Links in the chain of adversity following job loss: How financial strain and loss of personal control lead to depression, impaired functioning, and poor health. Journal of Occupational Health Psychology, 7, 302-312.

SAMHSA (2014). Results from the 2013 National Survey on Drug Use and Health: Summary of national findings (DHHS Publication No. SMA 14-4863). Retrieved from http://www.samhsa.gov/data/sites/default/files/NSDUHresultsPDFWHTML2013/ Web/NSDUHresults2013.pdf

SAMHSA (2014). Results from the 2014 National Survey on Drug Use and Health: Detailed tables. Retrieved from 
http://www.samhsa.gov/data/sites/default/files/NSDUH-DetTabs2014/NSDUHDetTabs2014.htm\#tab2-41b

Sayette, M. A. (1993). An appraisal-disruption model of alcohol's effects on stress responses in social drinkers. Psychological Bulletin, 114, 459-476.

Schaufeli, W. B., \& Bakker, A. B. (2004). Job demands, job resources, and their relationship with burnout and engagement: A multi-sample study. Journal of Organizational Behavior, 25, 293-315.

Schaufeli, W. B., \& Peeters, M. C. (2000). Job stress and burnout among correctional officers: A literature review. International Journal of Stress Management, 7, 1948.

Schnall, P. L., Schwartz, J. E., Landsbergis, P. A., Warren, K., \& Pickering, T. G. (1992). Relation between job strain, alcohol, and ambulatory blood pressure. Hypertension, 19, 488-494.

Seeman, M., \& Anderson, C. S. (1983). Alienation and alcohol: The role of work, mastery, and community in drinking behavior. American Sociological Review, 48, $60-77$.

Siegrist, J., \& Rödel, A. (2006). Work stress and health risk behavior. Scandinavian Journal of Work, Environment \& Health, 32, 473-481.

Siltaloppi, M., Kinnunen, U., \& Feldt, T. (2009). Recovery experiences as moderators between psychosocial work characteristics and occupational well-being. Work \& Stress, 23, 330-348. 
Sobel, M. E. (1982). Asymptotic confidence intervals for indirect effects in structural equation models. Sociological Methodology, 13, 290-312.

Sonnentag, S., \& Bayer, U. V. (2005). Switching off mentally: Predictors and consequences of psychological detachment from work during off-job time. Journal of Occupational Health Psychology, 10, 393-414.

Sonnentag, S., \& Fritz, C. (2007). The Recovery Experience Questionnaire: Development and validation of a measure for assessing recuperation and unwinding from work. Journal of Occupational Health Psychology, 12, 204-221.

Sonnentag, S., \& Fritz, C. (2014). Recovery from job stress: The stressor-detachment model as an integrative framework. Journal of Organizational Behavior, 36, S72S103.

Sonnentag, S., \& Grant, A. M. (2012). Doing good at work feels good at home, but not right away: When and why perceived prosocial impact predicts positive affect. Personnel Psychology, 65, 495-530.

Sonnentag, S., \& Natter, E. (2004). Flight attendants' daily recovery from work: Is there no place like home?. International Journal of Stress Management, 11, 366-391. Sonnentag, S., Binnewies, C., \& Mojza, E. J. (2010). Staying well and engaged when demands are high: The role of psychological detachment. Journal of Applied Psychology, 95, 965-976. 
Sonnentag, S., Kuttler, I., \& Fritz, C. (2010). Job stressors, emotional exhaustion, and need for recovery: A multi-source study on the benefits of psychological detachment. Journal of Vocational Behavior, 76, 355-365.

Sonnentag, S., Mojza, E. J., Binnewies, C., \& Scholl, A. (2008). Being engaged at work and detached at home: A week-level study on work engagement, psychological detachment, and affect. Work \& Stress, 22, 257-276.

Spector, P. E., Zapf, D., Chen, P. Y., \& Frese, M. (2000). Why negative affectivity should not be controlled in job stress research: Don't throw out the baby with the bath water. Journal of Organizational Behavior, 21, 79-95.

Spicer, R. S., Miller, T. R., \& Smith, G. S. (2003). Worker substance use, workplace problems and the risk of occupational injury: A matched case-control study. Journal of Studies on Alcohol, 64, 570-578.

Staff, J., \& Uggen, C. (2003). The fruits of good work: Early work experiences and adolescent deviance. Journal of Research in Crime and Delinquency, 40, 263290.

Stahre, M., Roeber, J., Kanny, D., Brewer, R. D., \& Zhang, X. (2014). Contribution of Excessive Alcohol Consumption to Deaths and Years of Potential Life Lost in the United States. Preventing Chronic Disease, 11, E109.

Stockwell, T., Donath, S., Cooper-Stanbury, M., Chikritzhs, T., Catalano, P., \& Mateo, C. (2004). Under-reporting of alcohol consumption in household surveys: A 
comparison of quantity-frequency, graduated-frequency and recent recall. Addiction, 99, 1024-1033.

Stone, A. A., Kennedy-Moore, E., \& Neale, J. M. (1995). Association between daily coping and end-of-day mood. Health Psychology, 14, 341-349.

Swatt, M. L., Gibson, C. L., \& Piquero, N. L. (2007). Exploring the utility of general strain theory in explaining problematic alcohol consumption by police officers. Journal of Criminal Justice, 35, 596-611.

Swift, R., \& Davidson, D. (1998). Alcohol hangover. Alcohol Health Res World, 22, 5460.

Ten Brummelhuis, L. L., \& Bakker, A. B. (2012). A resource perspective on the workhome interface: The work-home resources model. American Psychologist, 67, $545-556$.

Thoits, P. A. (1995). Stress, coping, and social support processes: Where are we? What next?. Journal of Health and Social Behavior, 35, 53-79.

Triplett, R., Mullings, J. L., \& Scarborough, K. E. (1996). Work-related stress and coping among correctional officers: Implications from organizational literature. Journal of Criminal Justice, 24, 291-308. doi:10.1016/0047-2352(96)00018-9

Van Veldhoven, M. J. P. M., \& Meijman, T. F. (1994). The measurement of psychosocial job demands with a questionnaire (VBBA). Amsterdam: NIA.

Vasse, R. M., Nijhuis, F. J. N., \& Kok, G. (1998). Associations between work stress, alcohol consumption and sickness absence. Addiction, 93, 231-241. 
Wang, M., Liu, S., Zhan, Y., \& Shi, J. (2010). Daily work-family conflict and alcohol use: Testing the cross-level moderation effects of peer drinking norms and social support. Journal of Applied Psychology, 95, 377-386. doi:10.1037/a0018138

Watson, D., \& Clark, L. A. (1999). The PANAS-X: Manual for the positive and negative affect schedule-expanded form. Unpublished manuscript. University of Iowa, Iowa City.

Weir, H., Stewart, D. M., \& Morris, R. G. (2012). Problematic alcohol consumption by police officers and other protective service employees: A comparative analysis. Journal of Criminal Justice, 40, 72-82.

Wolff, J. M., Rospenda, K. M., Richman, J. A., Liu, L., \& Milner, L. A. (2013). Workfamily conflict and alcohol use: Examination of a moderated mediation model. Journal of Addictive Diseases, 32, 85-98.

Xanthopoulou, D., Bakker, A. B., Demerouti, E., \& Schaufeli, W. B. (2007). The role of personal resources in the job demands-resources model. International Journal of Stress Management, 14, 121-141.

Xanthopoulou, D., Bakker, A. B., Dollard, M. F., Demerouti, E., Schaufeli, W. B., Taris, T. W., \& Schreurs, P. J. (2007). When do job demands particularly predict burnout? The moderating role of job resources. Journal of Managerial Psychology, 22, 766-786. 
Zapf, D., Dormann, C., \& Frese, M. (1996). Longitudinal studies in organizational stress research: A review of the literature with reference to methodological issues. Journal of Occupational Health Psychology, 1, 145-169.

Zwerling, C., Sprince, N. L., Wallace, R. B., Davis, C. S., Whitten, P. S., \& Heeringa, S. G. (1996). Alcohol and occupational injuries among older workers. Accident Analysis \& Prevention, 28, 371-376. 